\title{
Subduction over the Southern Indian Ocean in a High-Resolution Atmosphere-Ocean Coupled Model
}

\author{
Mei-Man LeE And A. J. George Nurser \\ National Oceanography Centre, Southampton, Southampton, United Kingdom \\ I. STEVENS \\ School of Mathematics, University of East Anglia, Norwich, United Kingdom \\ JEAN-BAPTISTE SALLÉE* \\ Centre for Australian Weather and Climate Research, CSIRO Marine and Atmospheric Research, \\ Hobart, Tasmania, Australia
}

(Manuscript received 10 June 2010, in final form 12 January 2011)

\begin{abstract}
This study examines the subduction of the Subantarctic Mode Water in the Indian Ocean in an oceanatmosphere coupled model in which the ocean component is eddy permitting. The purpose is to assess how sensitive the simulated mode water is to the horizontal resolution in the ocean by comparing with a coarseresolution ocean coupled model. Subduction of water mass is principally set by the depth of the winter mixed layer. It is found that the path of the Agulhas Current system in the model with an eddy-permitting ocean is different from that with a coarse-resolution ocean. This results in a greater surface heat loss over the Agulhas Return Current and a deeper winter mixed layer downstream in the eddy-permitting ocean coupled model. The winter mixed layer depth in the eddy-permitting ocean compares well to the observations, whereas the winter mixed layer depth in the coarse-resolution ocean coupled model is too shallow and has the wrong spatial structure. To quantify the impacts of different winter mixed depths on the subduction, a way to diagnose local subduction is proposed that includes eddy subduction. It shows that the subduction in the eddypermitting model is closer to the observations in terms of the magnitudes and the locations. Eddies in the eddy-permitting ocean are found to 1) increase stratification and thus oppose the densification by northward Ekman flow and 2) increase subduction locally. These effects of eddies are not well reproduced by the eddy parameterization in the coarse-resolution ocean coupled model.
\end{abstract}

\section{Introduction}

Mode waters play a crucial role in the global biogeochemical cycle in that atmospheric $\mathrm{CO}_{2}$ is taken up during the formation of mode waters and subsequently transported to other parts of the ocean (Sabine et al. 2004). Subantarctic Mode Water (SAMW) is a thick homogeneous layer formed by deep winter convection

* Current affiliation: British Antarctic Survey, Cambridge, United Kingdom.

Corresponding author address: Dr. Mei-Man Lee, Ocean Modelling and Forecasting, National Oceanography Centre, Southampton, Southampton SO14 3ZH, United Kingdom.

E-mail:mmlee@noc.soton.ac.uk on the northern flank of the Subantarctic Front (SAF). The conventional view is that a combination of surface cooling and northward Ekman transport of cold and fresh surface waters sets the formation of the SAMW (McCartney 1982; England et al. 1993). However, the controlling mechanism for the formation and subduction of the SAMW remains unclear because (a) surface fluxes in the Southern Ocean are poorly known, (b) the influence of the Antarctic Circumpolar Current (ACC) and western boundary currents on the watermass formation downstream are not well understood, and (c) the role of eddies is uncertain. So, it is not surprising that the subduction rate of mode waters in the Southern Ocean is one of the least agreed-upon quantities among observationbased estimates as well as among climate models (Sloyan and Kamenkovich 2007). 
Theory suggests that the convergence of lateral eddy diffusive flux in the mixed layer provides an additional forcing to the watermass formation (Marshall 1997). In an idealized modeling study, Cerovečki and Marshall (2008) demonstrated that the eddy heat flux divergence is comparable to the surface heat flux and is of opposite sign. Karstensen and Quadfasel (2002) found that the watermass formation rates inferred from surface fluxes are similar to those inferred from the tracer age method, which implies that the lateral eddy diffusion is unimportant (though this conclusion is qualified by the large uncertainties of the surface fluxes). Recently, Sallée et al. (2006) estimated the eddy diffusive heat flux, from parameterization using sea surface temperature (SST) from satellites and eddy diffusivity from drifters, and found that eddy diffusion gave a large cooling over the Kerguelen Plateau, upstream of where the mixed layer is deep. The fact that eddies operate on the upstream rather than within the region where the mixed layer is the deepest suggests the far-field influence cannot be ignored.

Apart from the diapycnic eddy diffusion in the mixed layer, eddies also induce subduction. On a given isopycnal, eddy subduction can be linked to the alongisopycnal eddy transport where the isopycnal slopes down below the mixed layer base (Marshall 1997). The eddy-induced transport below the mixed layer base has been estimated from parameterizations to be about $28 \mathrm{~Sv}\left(\mathrm{~Sv} \equiv 10^{6} \mathrm{~m}^{3} \mathrm{~s}^{-1}\right)$ integrated over the Southern Ocean (Karsten and Marshall 2002; Sallée et al. 2010). In contrast, Karstensen and Quadfasel (2002) suggested that the integrated eddy subduction is negligible based on the fact that the kinematic subduction (CushmanRoisin 1987) from time-mean flows gave a similar subduction rate to that from the tracer age method.

Ideally, one would hope that general circulation models should clarify the relative roles of surface fluxes, circulation patterns, and eddies that result in the formation of SAMW. The main drawback for ocean-only models is the lack of feedback between the ocean and atmosphere, which is vital for understanding the air-sea processes involved in watermass formation. Moreover, ocean-only models are forced by surface fluxes data and it is known that over the Southern Ocean the differences between various estimates of surface flux are particularly large (Grist and Josey 2003). For oceanatmosphere coupled models, the air-sea fluxes are consistent with the ocean state but eddies are inadequately resolved, in comparison to ocean-only models that can be run at resolutions of up to $1 / 12^{\circ}$.

In this study, we examine the subduction rate in an atmosphere-ocean coupled climate model with two different horizontal grids for the ocean, at $1 / 3^{\circ}$ and $1^{\circ}$ resolution. The purpose is to assess the sensitivity of subduction to the horizontal resolution for the ocean component and to address how well eddy effects are parameterized in the coarse-resolution model. Although the ocean component is only eddy permitting at best, it is currently one of the high-end climate models in terms of its ocean resolution and so careful assessment is crucial to improving future climate models. We will mostly consider the southern Indian Ocean unless mentioned otherwise.

\section{Coupled models and observation data}

The High-Resolution Global Environmental Model (HiGEM) is an ocean-atmosphere coupled general circulation model that is based on the Hadley Centre Global Environmental Model (HadGEM). We use versions HiGEM1.2 and HadGEM1.2 for our study. Full descriptions and basic evaluations of the HiGEM model can be found in Shaffrey et al. (2009). Here, we give some model parameters that are relevant to this study. For HiGEM, the horizontal resolution is $1.25^{\circ} \times 0.83^{\circ}$ for the atmosphere and $1 / 3^{\circ} \times 1 / 3^{\circ}$ for the ocean. For HadGEM, the horizontal resolution is $1.875^{\circ} \times 1.25^{\circ}$ for the atmosphere and $1^{\circ} \times 1^{\circ}$ for the ocean (increasing to $1 / 3^{\circ}$ between $30^{\circ} \mathrm{S}$ and $30^{\circ} \mathrm{N}$ ). The Gent and McWilliams (1980, hereafter GM) parameterization was employed in HadGEM but not in HiGEM. The horizontally varying, depth-independent eddy thickness diffusivity is determined according to Visbeck et al. (1997). The timemean thickness diffusivity in HadGEM for the Indian Ocean is shown later (Fig. 12, bottom right). The maximum value is about $2000 \mathrm{~m}^{2} \mathrm{~s}^{-1}$ at $42^{\circ} \mathrm{S}, 50^{\circ}-70^{\circ} \mathrm{E}$ and $52^{\circ} \mathrm{S}, 140^{\circ} \mathrm{E}$. The lateral mixing of tracers uses the isopycnal formulation with constant isopycnal diffusivity $500 \mathrm{~m}^{2} \mathrm{~s}^{-1}$. The implementation uses the skew flux following Griffies et al. (1998) and the isopycnal slopes are tapered toward 0 if the slopes exceed 0.003 . The tapering applies to both the thickness diffusion and isopycnic diffusion. In addition, tracers at the top two levels $(\sim 20 \mathrm{~m})$ are also mixed horizontally using a biharmonic scheme. The mixed layer scheme follows the example of Kraus and Turner (1967). The ocean is initialized from rest with tracers from the $1 / 4^{\circ}$ World Ocean Atlas 2001 (Boyer et al. 2005). The diagnosis in this study uses 5-day mean data from years $90-100$ of the run.

\section{Surface properties}

One noticeable improvement as a result of the increased resolution in the ocean is seen in the flow speed and the spatial scale of fronts in the ACC (Fig. 1). The HiGEM model shows a series of multiple jets with a width of about $100 \mathrm{~km}$ meandering around topography at speeds of about $20-40 \mathrm{~cm} \mathrm{~s}^{-1}$. In contrast, there are fewer jets in HadGEM and the scale of the jets is much larger. 

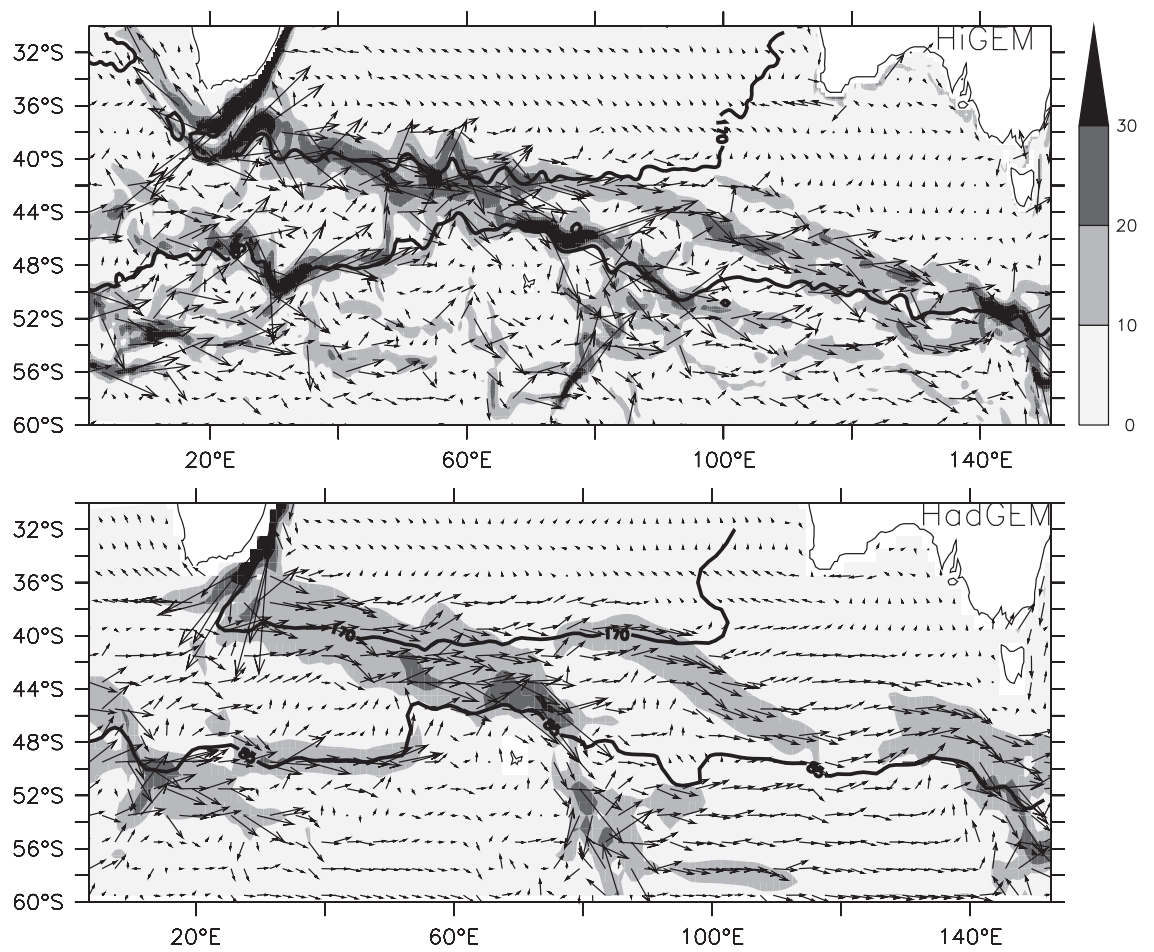

FIG. 1. The 10-yr mean fields from (top) HiGEM and (bottom) HadGEM for the upper400-m averaged velocity (vectors) and speed (shadings, $\mathrm{cm} \mathrm{s}^{-1}$ ). The barotropic transports of 170 and 85 Sv (thick lines) are used to define the STF and SAF, respectively.

For the convenience of discussion later, we use given values of the barotropic transport streamfunction to define the Subtropical (170 Sv) and Subantarctic (85 Sv) Fronts (STF and SAF, respectively). These two fronts are defined so that they coincide with the fast flows when overlaid with the top-400-m mean speed (Fig. 1). The contrast of the jet structure between the two models is also illustrated in the meridional sections of the potential density (referenced to the surface) at $75^{\circ} \mathrm{E}$ (Fig. 2, left). HiGEM has two well-defined fronts, corresponding to our definition of STF and SAF. In HadGEM the two jets are not so well separated and have much weaker gradients. To compare with the observations, we use the combination of two distinct datasets: the Argo float database and the ship-based Southern Ocean Data Base (SODB; see information online at http://woceSOatlas. tamu.edu). Overall, in HiGEM the vertical structure of the density compares well with the Argo-SODB data, although the fronts are steeper in HiGEM.

The horizontal fields of meanders and eddies in HiGEM are illustrated from the monthly mean SST for March (Fig. 2, right). In contrast, the SST field in HadGEM is nearly zonal. The observational data used for comparison are the combined Tropical Rainfall Measuring Microwave Imager (TMI) and Advanced Microwave Scanning Radiometer (AMSR) satellite SST data at $0.5^{\circ}$ resolution. The SST results in HiGEM resembles the satellite data in terms of the tighter boundary current and the zonal asymmetry of warm and cold waters. The eddy activity is also well simulated in HiGEM, as illustrated by the RMS of the sea surface height (SSH) anomaly based on 5-day mean data (Fig. 3, left). This pattern of activity compares well with the satellite altimeter data from the Developing Use of Altimetry for Climate Studies (DUACS) (at $0.25^{\circ}$ resolution), which is a dataset based on two satellites (information online at http://www.aviso.oceanobs.com/en/ data/products/sea-surface-height-products/global/msla/ index.html). The eddy activity is high along the STF, peaking in the Agulhas retroflection region. It gradually weakens eastward until the Kerguelen Plateau at $80^{\circ} \mathrm{E}$, where the STF and SAF converge. The zonal averages over $0^{\circ}-150^{\circ} \mathrm{E}$ show that the SSH variability in $\mathrm{HiGEM}$ is only slightly lower than the satellite data whereas the SSH variability in HadGEM is much lower (Fig. 3, insert figure in the middle-left panel).

It is known that the separation and retroflection of the Agulhas Current are better resolved as the resolution increases (Boudra and Chassignet 1988). Figure 4 (the superimposed STF in the bottom-left panel) illustrates that the Agulhas Current in HiGEM is tighter and the Agulhas Return Current has more spatial variations. 
HiGEM

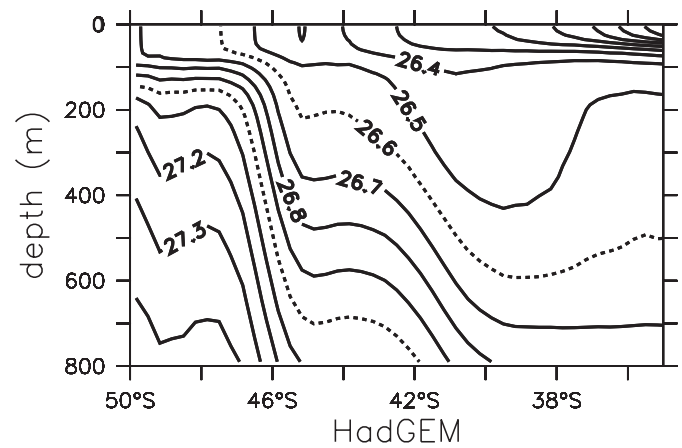

HadGEM
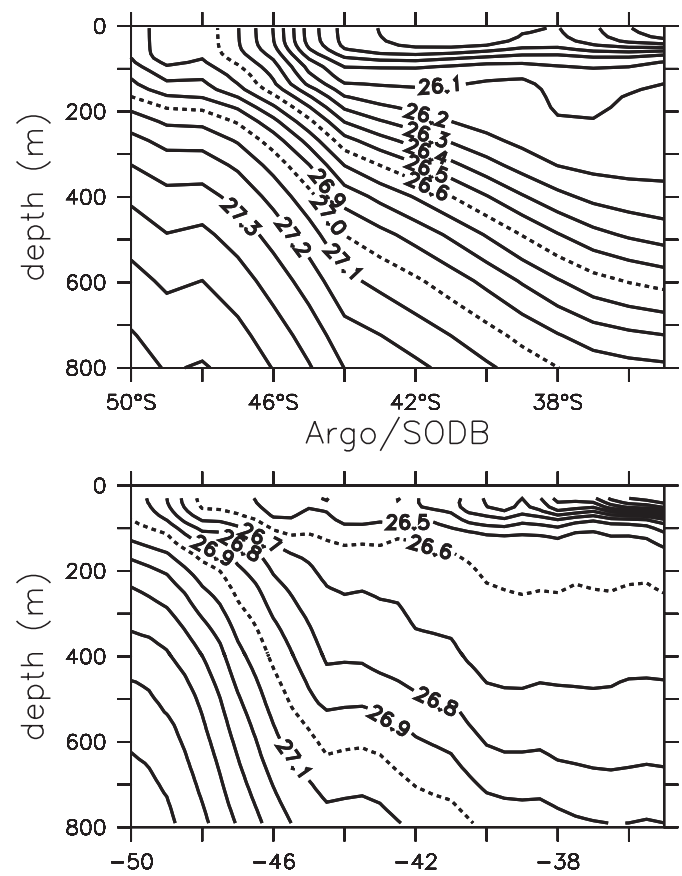

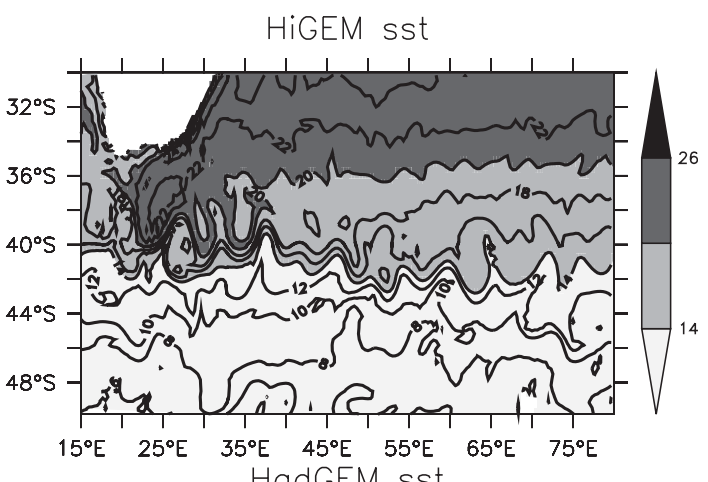

HadGEM sst
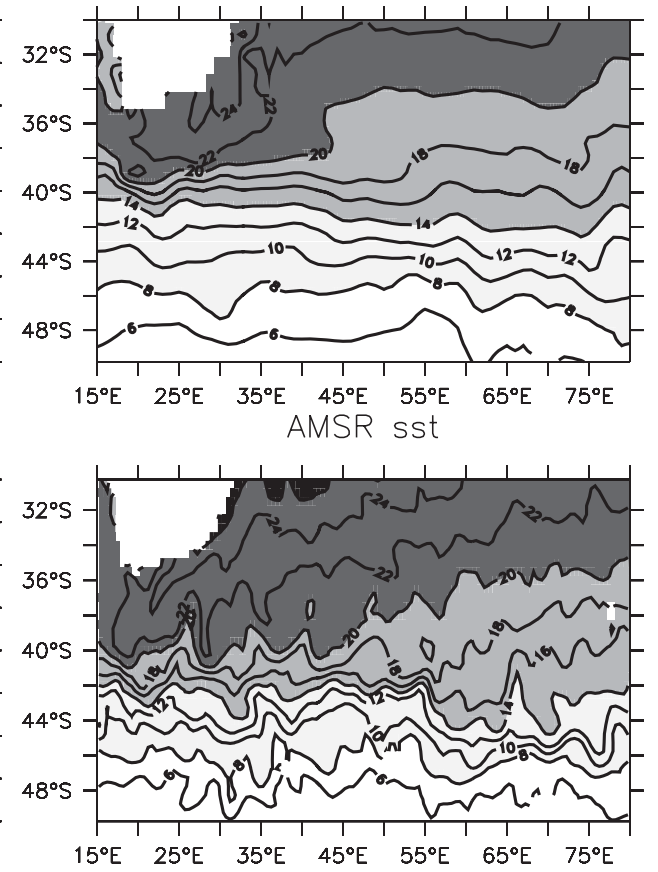

FIG. 2. (left) Meridional sections of the time-mean density at $75^{\circ} \mathrm{E}$, from (top) HiGEM and (middle) HadGEM, respectively. (bottom) Results from the combined Argo-SODB dataset. The contour interval is $0.1 \mathrm{~kg} \mathrm{~m}^{-3}$ and, for comparison, dotted contours mark 26.6 and $27.0 \mathrm{~kg} \mathrm{~m}^{-3}$. (right) The March mean SST at year 2060 from (top) HiGEM and (middle) HadGEM, respectively, and at year 2003 from (bottom) AMSR. The contour interval is $2^{\circ} \mathrm{C}$, with shadings shown for comparison.

The Agulhas Current is usually characterized as the warm southward boundary current. If we compare the $20^{\circ} \mathrm{C}$ contours in the models to those in observations, then neither model is doing particularly well (Fig. 4, top two panels). To compare like with like, we follow the temperature contours of the coldest waters adjacent to the east coast of Africa to decide how far south the Agulhas Current reaches. The Agulhas Current in HiGEM reaches about $40^{\circ} \mathrm{S}$ (following the $18^{\circ} \mathrm{C}$ black contour), while in HadGEM the Agulhas Current stays close to the coast until reaching the tip of the continent and then flows southward to about $38^{\circ} \mathrm{S}$ (following the $20^{\circ} \mathrm{C}$ black contour). The TMI-AMSR satellite data show that the Agulhas Current reaches $39.5^{\circ} \mathrm{S}$ (following the $20^{\circ} \mathrm{C}$ white contour). In this respect, the Agulhas Current reaches farther south than the observations by about $0.5^{\circ}$ in HiGEM and falls short by about $1.5^{\circ}$ in HadGEM.

The SST difference between the two models shows that HiGEM is warmer than HadGEM by as much as $4^{\circ} \mathrm{C}$ south of $40^{\circ} \mathrm{S}$ (Fig. 4, bottom left). The cause for this warmer SST in HiGEM could be due to the warm Agulhas Current reaching farther south after passing the tip of South Africa. The zonal variations of the SST difference are associated with the meandering STF in HiGEM (superimposed on the bottom-left panel in Fig. 4). Where the STF in HiGEM meanders south, SST is warmer there and vice versa. Farther southward, the 

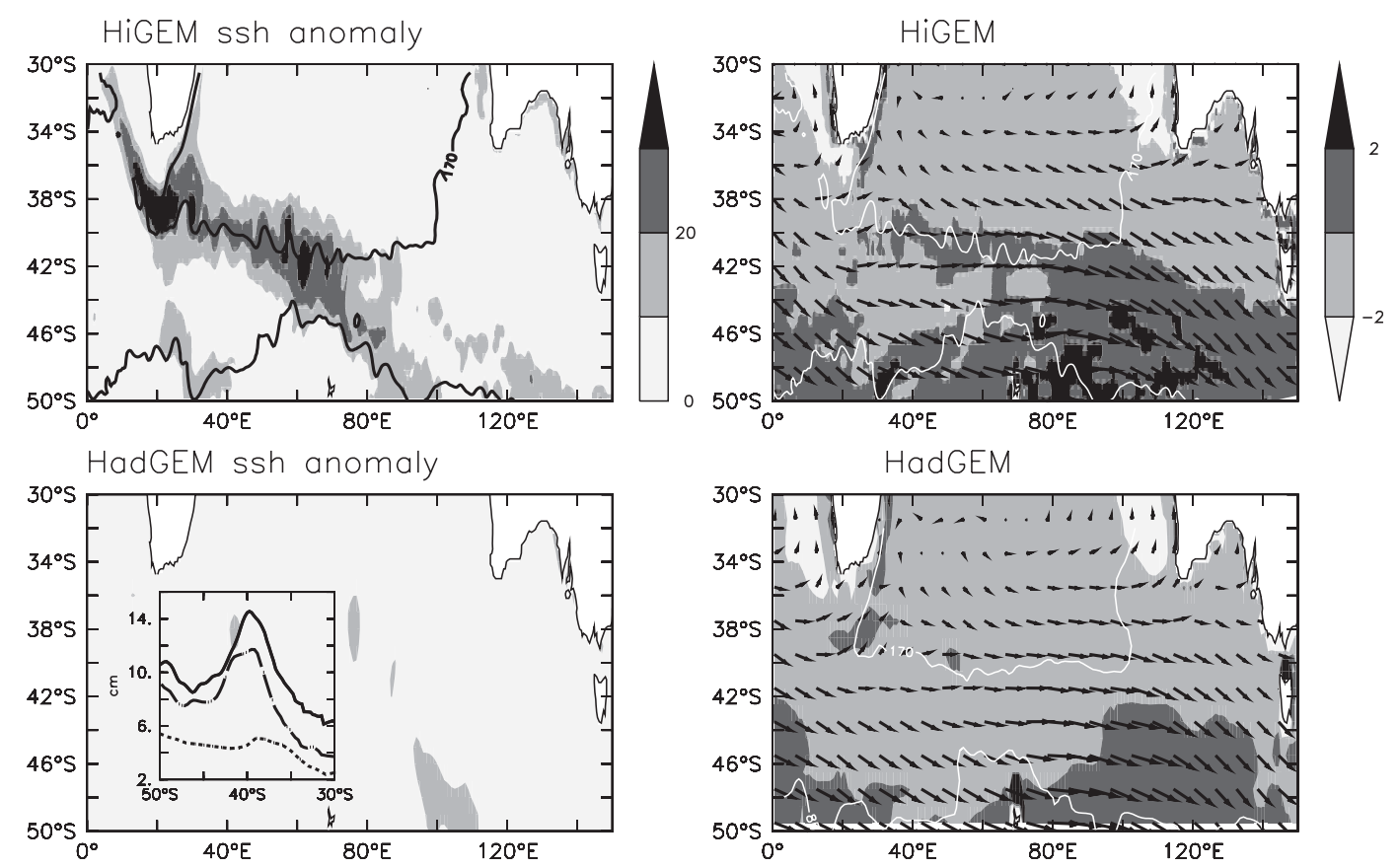

DUACS ssh anomaly
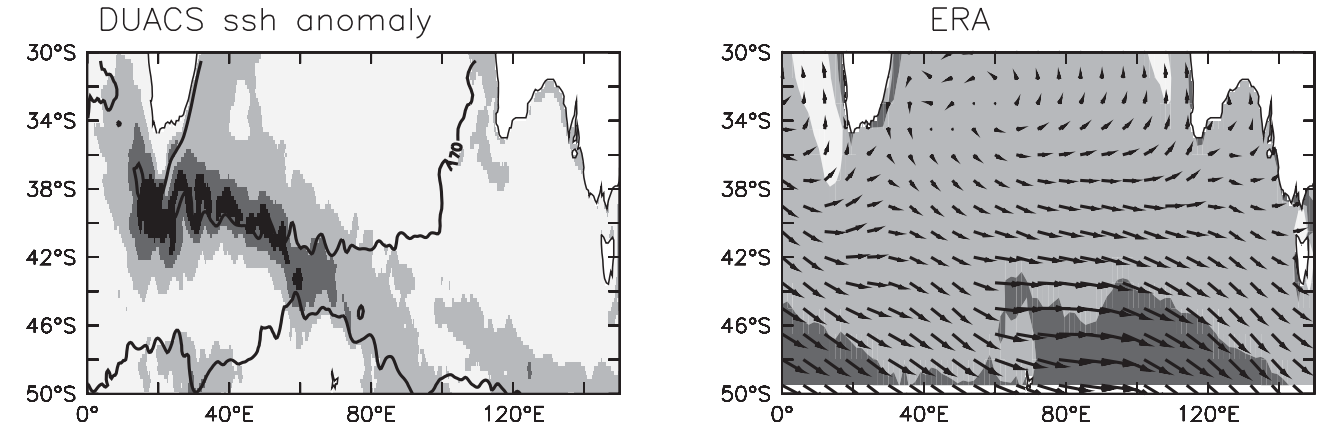

FIG. 3. (left) Shadings show the RMSs of the SSH anomaly (cm) over the 10 -yr period from (top) HiGEM, (middle) HadGEM, and (bottom) DUACS. The inserted plot in the middle panel is the zonal average over $0^{\circ}-150^{\circ} \mathrm{E}$ of the SSH anomaly from satellites data DUACS (solid line), HiGEM (dashed line), and HadGEM (dotted line). (right) Time-mean wind stress (vectors) and Ekman pumping (shadings; $10^{-6} \mathrm{~m} \mathrm{~s}^{-1}$ ) from (top) HiGEM, (middle) HadGEM, and (bottom) ERA. The SAF and STF are superimposed in black contours in the left panels and in white contours in the right panels.

extension of the Agulhas Current in HiGEM can influence SSTs downstream as warmer waters are advected along the STF. In addition, at $50^{\circ}-70^{\circ} \mathrm{E}$, where the STF and SAF converge, the warmer SST in HiGEM can also propagate to a greater meridional extent, as seen from the relatively larger SST difference near $70^{\circ} \mathrm{E}$.

In a coupled system, the surface air temperature (SAT) warms in response to the warm Agulhas Return Current. However, as strong westerly winds move across the zonal SST gradient, air parcels do not equilibrate instantly with the underlying SST changes. Thus, the region of large airsea temperature difference is shaped by the southward extent of the Agulhas Return Current (shadings in the top two panels of Fig. 4). In HiGEM, the region of large airsea temperature difference is centered at $40^{\circ} \mathrm{S}$ with variations along the meandering Agulhas Return Current. In contrast, in HadGEM the region of large air-sea temperature difference is centered at $38^{\circ} \mathrm{S}$ and with fewer spatial variations.

The SST difference in the two models is still larger than the compensating air temperature difference. This may be understood from the (approximated) steadystate advective-diffusive balance averaged vertically over the atmospheric boundary layer:

$$
T_{a, e}-T_{a, w} \sim \frac{\mathcal{H}}{\rho_{a} c_{p} h U} L
$$

where $T_{a}$ is the vertically averaged air temperature, $\mathcal{H}$ is the sensible heat flux, $\rho_{a}$ is the air density, $c_{p}$ is the heat 

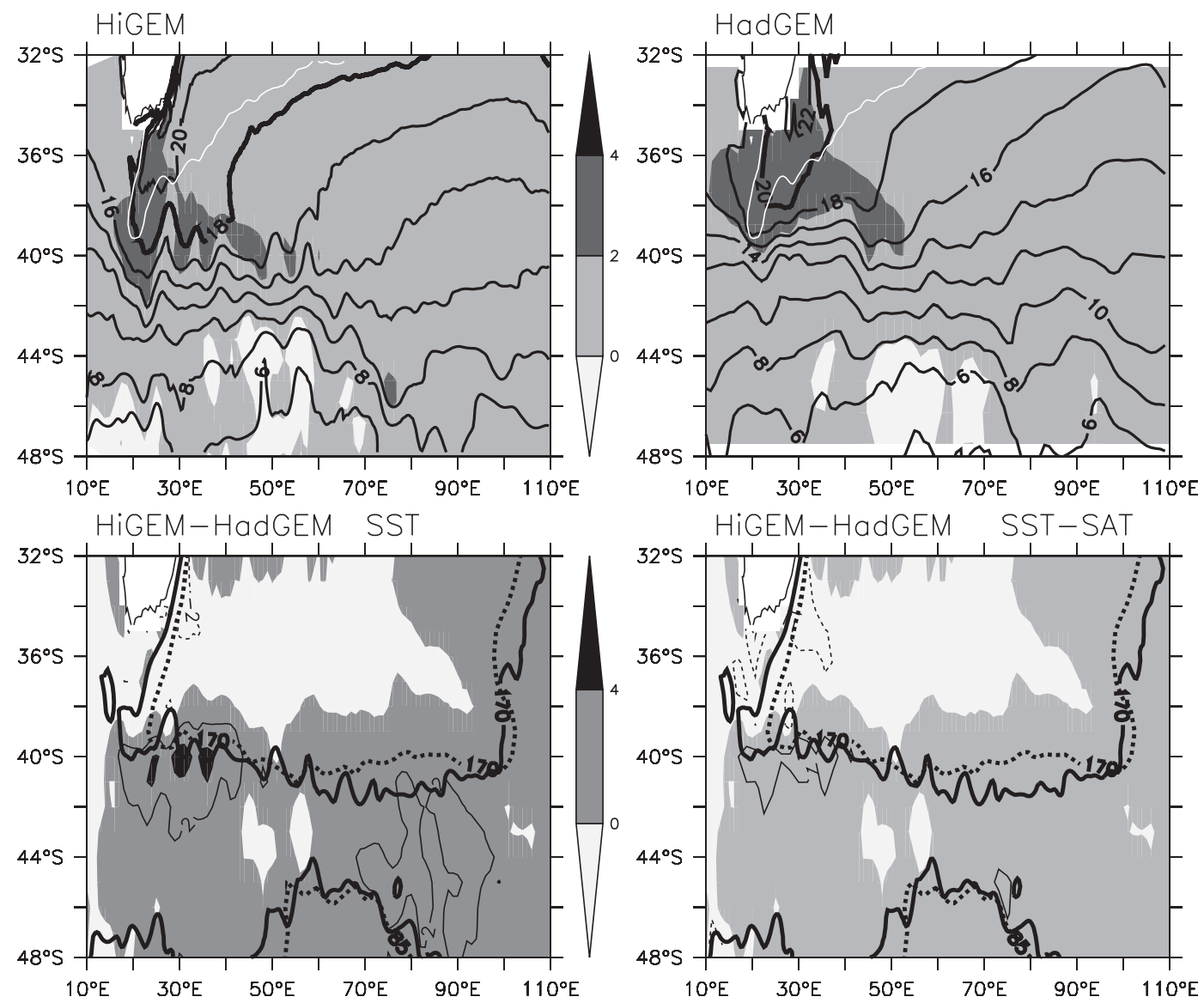

FIG. 4. The 10-yr mean SST $\left(2^{\circ} \mathrm{C}\right.$ contour interval) from (top left) HiGEM and (top right) HadGEM. The highlighted dark contours indicate $18^{\circ} \mathrm{C}$ in HiGEM and $20^{\circ} \mathrm{C}$ in HadGEM. The white contours indicate $20^{\circ} \mathrm{C}$ from the time mean (2002-07) SST of TMI-AMSR data. The shadings in the top two panels are the air-sea temperature difference (SST $-\mathrm{SAT}$ ), with the lightest shading for $\leq 0^{\circ} \mathrm{C}$. (bottom left) The SST from HiGEM-HadGEM with the darker shading for $>4^{\circ} \mathrm{C}$, intermediate shading for $>0^{\circ} \mathrm{C}$ and $<4^{\circ} \mathrm{C}$, and the lightest shading for $<0^{\circ} \mathrm{C}$, with a contour interval of $2^{\circ} \mathrm{C}$. (bottom right) The $(\mathrm{SST}-\mathrm{SAT})_{\mathrm{HiGEM}}-(\mathrm{SST}-\mathrm{SAT})_{\mathrm{HadGEM}}$ with the darker shading for $>0^{\circ} \mathrm{C}$, with a $1^{\circ} \mathrm{C}$ interval. The STF and SAF are superimposed in the bottom two panels with the dark solid contours for HiGEM and the dark dotted contours for HadGEM.

capacity of air, $L$ is the length scale, $U$ is the vertically averaged wind speed, and $h$ is the boundary layer depth. The subscript $e$ is at the location with warmer SSTs and $w$ is on the western side of that. For simplicity, we assume $\mathcal{H}$ is proportional to the air-sea temperature difference and so

$$
T_{a, e}-T_{a, w} \sim \alpha\left(\operatorname{SST}_{e}-T_{a, e}\right),
$$

where $\alpha$ is a constant. The air temperature difference between HiGEM and HadGEM is relatively smaller to the west of the Agulhas Return Current, so we ignore the $T_{a, w}$ difference between HiGEM and HadGEM. Thus, the air temperature difference between HiGEM and HadGEM at the location of the Agulhas Return Current is

$$
\begin{aligned}
\left(T_{a}^{\mathrm{Hi}}-T_{a}^{\mathrm{Had}}\right) & \sim \alpha\left(\mathrm{SST}^{\mathrm{Hi}}-\mathrm{SST}^{\mathrm{Had}}\right)-\alpha\left(T_{a}^{\mathrm{Hi}}-T_{a}^{\mathrm{Had}}\right), \\
& \sim \frac{\alpha}{1+\alpha}\left(\mathrm{SST}^{\mathrm{Hi}}-\mathrm{SST}^{\mathrm{Had}}\right) .
\end{aligned}
$$

where the superscripts $\mathrm{Hi}$ and Had indicate HiGEM and HadGEM, respectively, and the subscript $e$ is omitted.

The above equation implies that the air temperature difference between the two models is less than the SST difference between the two models. For example, at $40^{\circ} \mathrm{S}, 30^{\circ} \mathrm{E}$ over the Agulhas Return Current, although the SST in HiGEM is warmer than in the HadGEM by, say, $4^{\circ} \mathrm{C}$, the corresponding air temperature in HiGEM is not warmer by as much. As shown in Fig. 4 (bottom right), the SST-SAT in HiGEM is still larger than that in HadGEM by at least $1^{\circ} \mathrm{C}$ over this region. It should be said that for ocean-only models the lack of feedback 

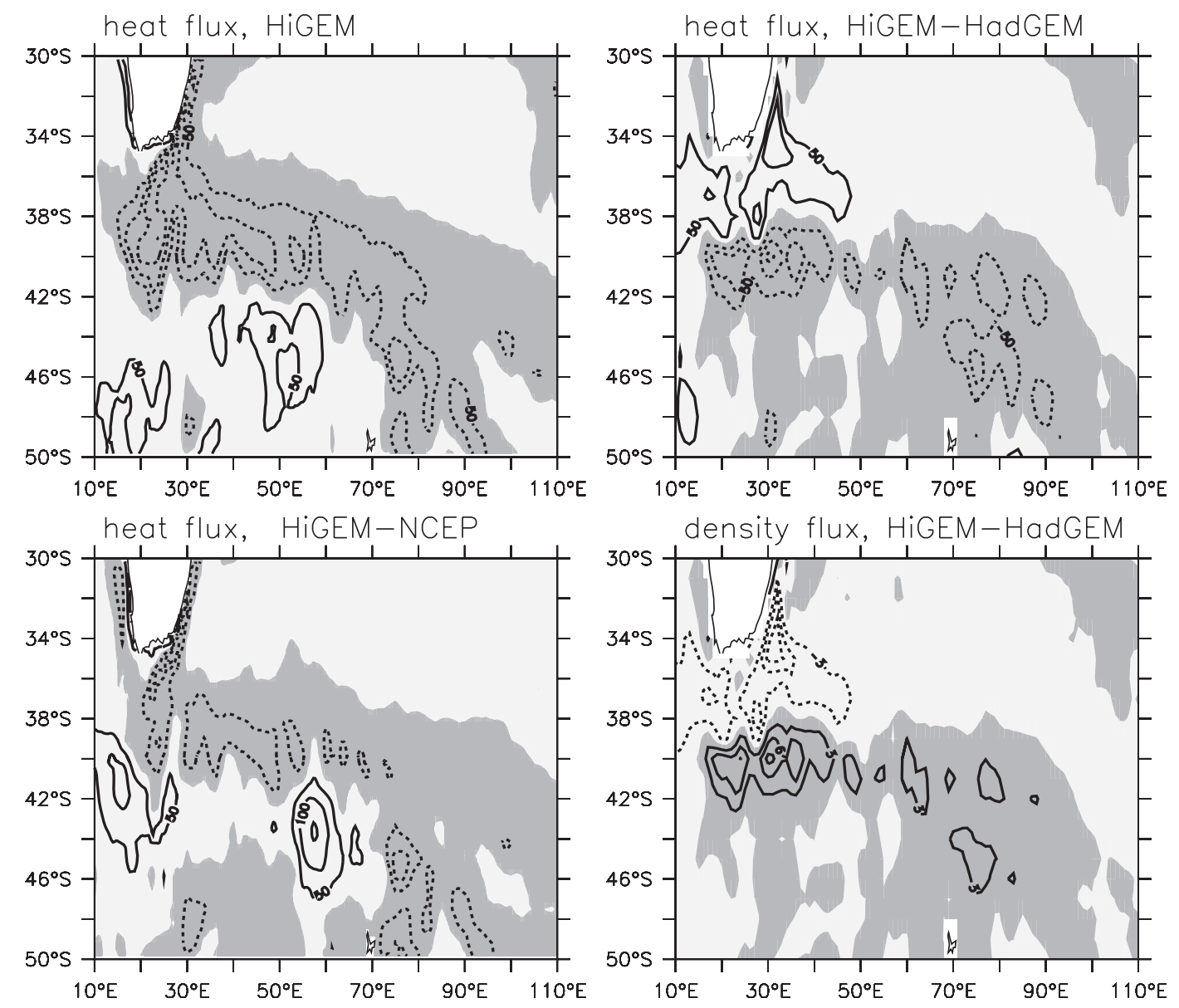

FIG. 5. The 10-yr mean heat fluxes: for (top left) HiGEM and (top right) HiGEM - HadGEM and (bottom left) HiGEM - NCEP. (bottom right) The density fluxes for HiGEM - HadGEM. For the heat flux, the contour interval is $50 \mathrm{~W} \mathrm{~m}^{-2}$ and shadings are for negative values (ocean heat loss). For the density flux, the contour interval is $3 \times$ $10^{-6} \mathrm{~kg} \mathrm{~m}^{-2} \mathrm{~s}^{-1}$, and positive values (density gain) are shaded.

between the ocean and atmosphere means that the air temperature will not be modified by the warmer SST and so there will be a greater air-sea temperature difference.

The impact of the air-sea temperature difference is manifested in the surface heat flux. In HiGEM, significant heat loss over the Agulhas Return Current is up to $180 \mathrm{~W} \mathrm{~m}^{-2}$ (Fig. 5, top left). HiGEM has an even greater heat loss than HadGEM south of $40^{\circ} \mathrm{S}$ (Fig. 5, top right). This is consistent with the larger air-sea temperature difference in HiGEM over the same region as seen from Fig. 4. We check whether other factors might also affect the heat fluxes by separating the heat flux into latent and sensible components and we find that the latter is the main component for the heat flux difference (not shown). Further diagnosis shows that the dominant term is the specific humidity component $(q-$ $q_{\text {sst }}$, where $q$ is specific humidity at the standard level and $q_{\text {sst }}$ is the specific humidity at the sea surface). As this term is also determined by the SST, we can say that the greater heat loss in HiGEM is largely caused by the warmer SST. For the density flux, it mainly reflects the pattern of heat flux (Fig. 5, bottom right). Around the area south of $40^{\circ} \mathrm{S}$, the greater heat loss is associated with positive density flux.

Comparing the heat flux in HiGEM to the data from the National Centers for Environmental Prediction (NCEP) shows a greater amount of heat loss in HiGEM along the belt of high eddy activity along the STF $\left(40^{\circ} \mathrm{S}\right.$, $\left.20^{\circ}-80^{\circ} \mathrm{E}\right)$ and on the north side of SAF $\left(46^{\circ} \mathrm{S}, 80^{\circ} \mathrm{E}\right)$ (Fig. 5, bottom left). The smaller amount of heat loss over the STF in NCEP could be due to data that are at coarse resolution (about $2^{\circ}$ ). This would be consistent with Rouault et al. (2003), in that the heat fluxes may be underestimated by the reanalysis data if the spatial resolution does not resolve the ocean fronts and eddies sufficiently.

For the discussions later, we also plot surface density and wind stress. The surface density field is very different in the two models with HiGEM being denser than 


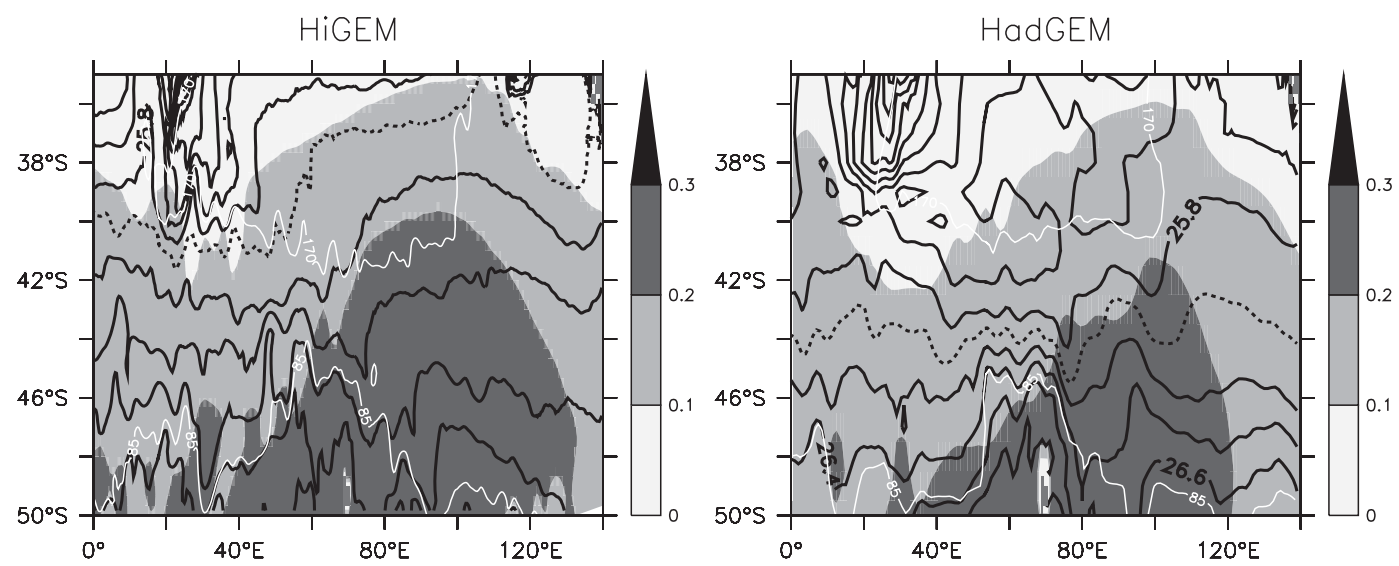

FIG. 6. The time-mean surface density for (left) HiGEM and (right) HadGEM, with $0.2 \mathrm{~kg} \mathrm{~m}^{-3}$ contours. The dotted contours mark $26.0 \mathrm{~kg} \mathrm{~m}^{-3}$ for comparison. The shadings are the RMSs of the wind stress in newtons per meter squared. The white contours mark the STF and SAF.

HadGEM (Fig. 6). Although HiGEM is warmer than HadGEM, it is saltier because the sea ice cover is less extensive, and so meltwaters do not penetrate so far north (Shaffrey et al. 2009). The different surface density fields in the models will affect the comparisons of the subduction later. The two models have similar wind stress and both compare well with the European Centre for Medium-Range Weather Forecasting (ECMWF) reanalysis data (ERA-Interim) (see Fig. 3 for wind stress vector and Fig. 6 for the RMS of the wind stress). However, Ekman upwelling is stronger in HiGEM than in both ERA and HadGEM (Fig. 3). Note the interesting feature of Ekman upwelling along the STF in HiGEM (Fig. 3).

In summary, we found that the Agulhas Current in HiGEM is tighter and continues farther south than that in HadGEM. This results in warmer SSTs in HiGEM south of the STF. Although the surface air temperature is locally warmer over the Agulhas Return Current, the SST difference between HiGEM and HadGEM is larger than the air temperature difference between the two models. Consequently, HiGEM has a greater heat loss along the southern flank of the STF. In the next section, we will see that the surface flux plays a major role in determining the mixed layer depth.

\section{Mixed layer depth}

The mixed layer depth (MLD) is calculated using the criterion $\Delta \rho \leq 0.03 \mathrm{~kg} \mathrm{~m}^{-3}$ between the surface and the base of the mixed layer. We use the mixed layer in September for our winter mixed layer (WML). In both models, the deep WML occurs on the north side of SAF around $120^{\circ}-140^{\circ} \mathrm{E}$, the region of SAMW formation
(Fig. 7). Along the northern flank of the SAF, the WML in HiGEM deepens gradually eastward reaching $570 \mathrm{~m}$ at $45^{\circ} \mathrm{S}, 120^{\circ} \mathrm{E}$. In contrast, the WML depth in HadGEM remains fairly uniform with values of $150-200 \mathrm{~m}$ over $45^{\circ} \mathrm{S}$, $80^{\circ}-120^{\circ} \mathrm{E}$

For the comparison with the observations, we use the combined Argo-SODB data to calculate the WML from each profile using the same criterion, $\Delta \rho \leq 0.03 \mathrm{~kg} \mathrm{~m}^{-3}$ (Sallée et al. 2006; Dong et al. 2008), and mapped climatological averages by a Loess fitting method (see Sallée et al. 2010 for more details) (Fig. 7, bottom left). The zonal structure of the WML in HiGEM compares well with the Argo-SODB data, showing a band of tilted deep WML between $60^{\circ}$ and $170^{\circ} \mathrm{E}$. We also compare with the climatology from de Boyer Montégut et al. (2004) (using $\Delta T \leq 0.2^{\circ} \mathrm{C}$ ) (Fig. 7, bottom right). The differences in the de Boyer Montégut et al. (2004) climatology resulting from using the criteria $\Delta T \leq 0.2^{\circ} \mathrm{C}$ or $\Delta \rho \leq 0.03 \mathrm{~kg} \mathrm{~m}^{-3}$ are small (Fig. 8, bottom right). The de Boyer Montégut et al. (2004) climatology is slightly shallower than the Argo-SODB data and has more distinct pockets of deep WML at $100^{\circ}$ and $126^{\circ} \mathrm{E}$ rather than the band of deep WML seen in HiGEM and in the Argo-SODB data. The discrepancy between de Boyer Montégut et al. (2004) and Argo-SODB is probably due to more winter data being available from the Argo floats.

Taking the zonal averages over $20^{\circ}-170^{\circ} \mathrm{E}$, the WML in HiGEM resembles closely that from the Argo-SODB data with a peak value of $260 \mathrm{~m}$ at $45^{\circ} \mathrm{S}$ (Fig. 8, bottom right). In comparison, the de Boyer Montégut et al. (2004) climatology is shallower by about $60 \mathrm{~m}$ at $45^{\circ} \mathrm{S}$. In HadGEM, the zonal mean WML is shallower than both climatologies and the Argo-SODB data over $45^{\circ}-50^{\circ} \mathrm{S}$. More important, the WML in HadGEM does not have 

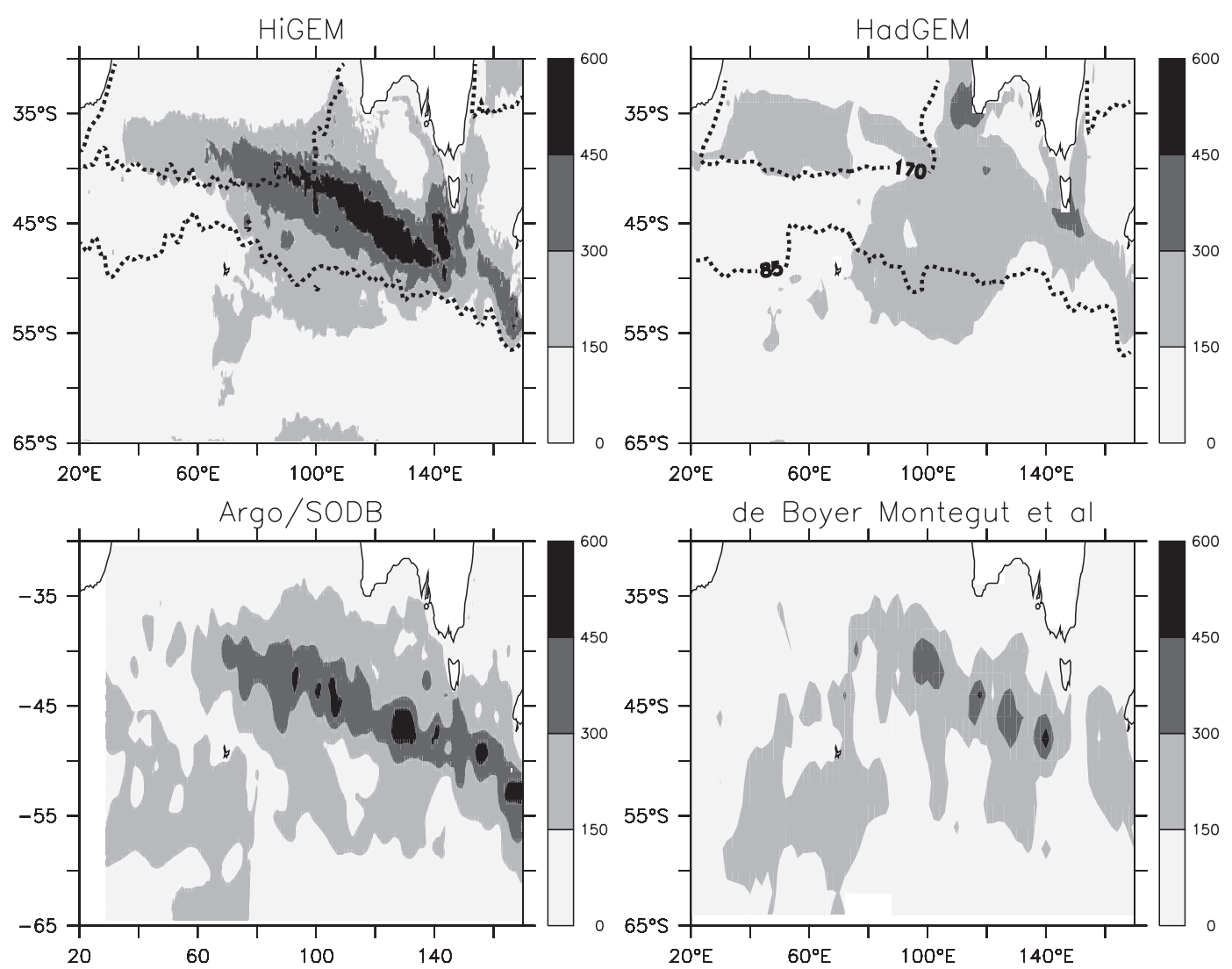

FIG. 7. The time-mean September MLD (shading) from (top left) HiGEM, (top right) HadGEM, (bottom left) Argo-SODB data, and (bottom right) de Boyer Montégut et al. (2004). The dotted contours in the top panels indicate the STF and SAF.

the latitudinal distribution found in HiGEM and in observations with the peak at $45^{\circ} \mathrm{S}$.

Overall, the spatial distribution of WML in HiGEM is closer to the observations than HadGEM, but it might be too deep. One possible reason for too deep mixed layer in HiGEM could be that the mesoscale eddies are underrepresented. It has been shown that by increasing the resolution from eddy permitting to eddy resolving, the WML at the eastern subpolar North Atlantic is shallowed by nearly $200 \mathrm{~m}$ (Oschlies 2002). Alternatively, studies show that submesoscale eddies are highly efficient in restratifying the upper ocean (Fox-Kemper et al. 2008). By including submesoscale process parameterization in models, the WML depth could also be improved (FoxKemper and Ferrari 2008).

The problem at hand involves explaining the very different WML structures between the two models. The deeper WML in HiGEM cannot be explained by its increased horizontal resolution since resolving eddies in the model would lead to a shallower mixed layer, as mentioned above. The following is an attempt to understand the causes of the different WMLs in the two models. The basic idea is that following the flow along the north side of the SAF the stratification has to change in order for the mixed layer to become deeper. With this in mind, we examine how the stratification integrated over the top $400 \mathrm{~m}$ of the water column is changed along the flow. That is, we are interested in the density excess at the surface relative to $400 \mathrm{~m}$ because the more negative this quantity is, the more strongly the fluid is stratified. The 400-m depth is chosen so that it covers most of the WML depth in HiGEM.

Using the density equation, the evolution of the vertically integrated stratification is

$$
\begin{aligned}
& \frac{\partial}{\partial t} \int_{-H}^{0}\left(\rho-\rho_{0}\right) d z+\int_{-H}^{0} \mathbf{u} \cdot \nabla \rho d z-\int_{-H}^{0} \mathbf{u}_{0} \cdot \nabla \rho_{0} d z \\
& \quad=\mathcal{W}+\mathcal{F}+\mathcal{D}
\end{aligned}
$$

where $\mathbf{u}$ is the horizontal velocity, $\rho$ is density, $H=$ $400 \mathrm{~m}$, and the subscript 0 denotes the variables are evaluated at $400 \mathrm{~m}$. The $\mathcal{W}=\int_{-H}^{0}\left[w_{0}\left(\partial \rho_{0} / \partial z\right)-\right.$ $w(\partial \rho / \partial z)] d z$ is the contribution from the vertical velocity 

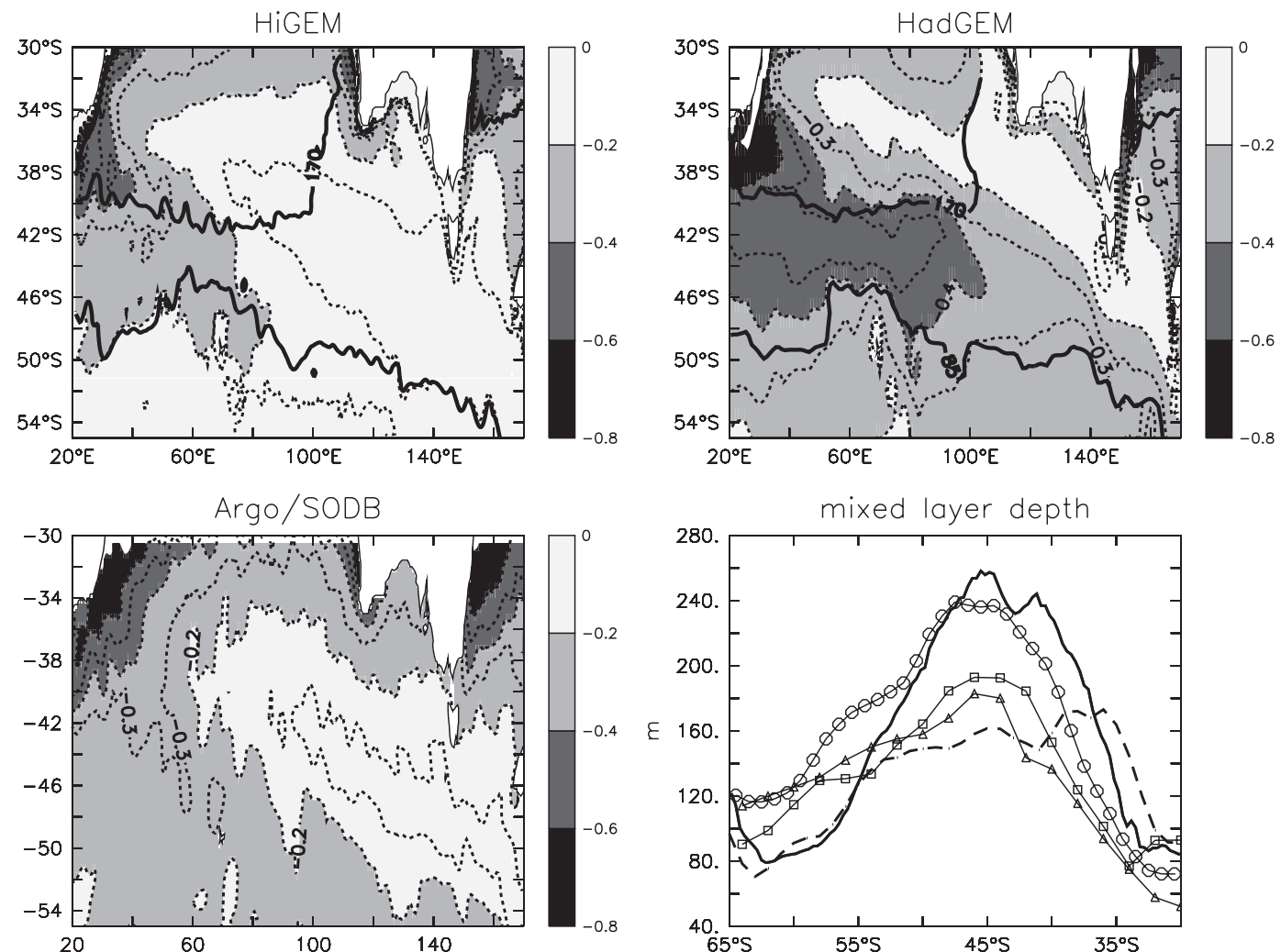

FIG. 8. The time-mean $(1 / H) \int_{-H}^{0}\left(\bar{\rho}-\bar{\rho}_{0}\right) d z$, where $\bar{\rho}_{0}$ is $\bar{\rho}$ at $400 \mathrm{~m}$ : (top left) HiGEM, (top right) HadGEM, and (bottom left) Argo-SODB data. The contour interval is $0.2 \mathrm{~kg} \mathrm{~m}^{-3}$. The superimposed dark solid contours are the STF and SAF. (bottom right) The zonal averages (over the Indian Ocean, $20^{\circ}-170^{\circ} \mathrm{E}$ ) of the WML depth from HiGEM (solid line), HadGEM (dashed line), Argo-SODB data (circles), and de Boyer Montégut et al. (2004) using $\Delta T \leq 0.2^{\circ} \mathrm{C}$ (triangles) and $\Delta \rho \leq 0.03 \mathrm{~kg} \mathrm{~m}^{-3}$ (squares).

$w$. The remaining terms are the surface forcing $\mathcal{F}$ and diffusion $\mathcal{D}$.

It would simplify the problem if we could consider how the stratification is advected by the flow at the base of the water column. Thus, we rewrite Eq. (4) as

$$
\begin{aligned}
\frac{\delta}{\delta t} \int_{-H}^{0}\left(\rho-\rho_{0}\right) d z+\int_{-H}^{0} \mathbf{u}_{0} \cdot \nabla\left(\rho-\rho_{0}\right) d z \\
\quad=-\int_{-H}^{0}\left(\mathbf{u}-\mathbf{u}_{0}\right) \cdot \nabla \rho d z+\mathcal{W}+\mathcal{F}+\mathcal{D} .
\end{aligned}
$$

The left-hand side is the evolution of the stratification following $\mathbf{u}_{0}$. The first term on the right-hand side represents the advection of the density due to the vertical shear of the flow. In the simplest case, where flows have no vertical shear and $\mathcal{W}=\mathcal{F}=\mathcal{D}=0$, the stratification will remain unchanged following $\mathbf{u}_{0}$ and so does the MLD.

As we are interested in the steady-state problem, Eq. (5) is further separated into time-mean and time-varying parts:

$$
\begin{aligned}
\frac{\partial}{\partial t} \int_{-H}^{0}\left(\bar{\rho}-\bar{\rho}_{0}\right) d z+\int_{-H}^{0} \overline{\mathbf{u}}_{0} \cdot \nabla\left(\bar{\rho}-\bar{\rho}_{0}\right) d z \\
=\int_{-H}^{0}-\left(\overline{\mathbf{u}}-\overline{\mathbf{u}}_{0}\right) \cdot \nabla \bar{\rho}-\overline{\left(\mathbf{u}^{\prime}-\mathbf{u}_{0}^{\prime}\right) \cdot \nabla \rho^{\prime}} \\
\quad-\overline{\mathbf{u}_{0}^{\prime} \cdot \nabla\left(\rho^{\prime}-\rho_{0}^{\prime}\right)} d z+\overline{\mathcal{W}}+\overline{\mathcal{F}}+\overline{\mathcal{D}},
\end{aligned}
$$

where the overbars show the time mean and the primes the deviation from the time mean. Now, the 1.h.s. shows the changes in the time-mean stratification following the time-mean flow at $400 \mathrm{~m}$. On the right-hand side, the first term is the advection of the time-mean density due to the time-mean vertical shear. The two time-varying terms represent the correlations between the eddy vertical shear and density gradient and between the eddy flows at $400 \mathrm{~m}$ and the time-varying stratification.

For the diagnosis of Eq. (6), the time mean is the 10-yr average and so the primed terms include eddies as well as seasonal cycles. However, in HadGEM we can separate seasonal cycles from eddies (given by GM velocity) 
and we have found that the seasonal cycle contribution is small (not shown). Figure 8 shows the time-mean stratification, $\int_{-H}^{0}\left(\bar{\rho}-\bar{\rho}_{0}\right) d z / H$, superimposed with the STF and SAF. On the whole, the stratification in HiGEM is weaker than that in HadGEM. This is related to the stronger fronts in HiGEM, as seen previously in Fig. 2. Following the flow between the two fronts, the stratification becomes weaker as the mixed layer becomes deeper. In HiGEM, there is a strong zonal gradient of stratification at $75^{\circ} \mathrm{E}$, implying that destratification occurs to the west of the deep WML region. In contrast, the strong zonal gradient of stratification in HadGEM occurs farther downstream at $100^{\circ} \mathrm{E}$ inside the deep WML region. Comparison to the Argo-SODB data reveals the remarkable similarity between HiGEM and the observation data, with both showing a large tilted area of low stratification (the lightest shading region) east of $60^{\circ} \mathrm{E}$.

The terms in Eq. (6) are diagnosed over the region between the STF and SAF by first latitudinally averaging between the fronts and then zonally averaging over $5^{\circ}$ longitudes (Fig. 9, top). The thick solid line is $\int_{-H}^{0} \overline{\mathbf{u}}_{0}$. $\nabla\left(\bar{\rho}-\bar{\rho}_{0}\right) d z$ (a positive value means that $\bar{\rho}-\bar{\rho}_{0}$ becomes less negative following $\overline{\mathbf{u}}_{0}$, so the water column is less stratified following $\overline{\mathbf{u}}_{0}$ ). In HiGEM, the stratification changes most at $75^{\circ} \mathrm{E}$, roughly the region of the Kerguelen Plateau. The surface forcing (the dashed line) is strongly correlated with the along-flow stratification change, especially at $70^{\circ}-75^{\circ} \mathrm{E}$, where the stratification is weakened most. The contribution from the advection [the sum of the first three terms on the r.h.s. of Eq. (6)] (dotted line) is relatively small. The remaining term $(\overline{\mathcal{W}}+\overline{\mathcal{D}})$ (thin solid line) is generally small except at $30^{\circ}, 40^{\circ}$, and $60^{\circ}-70^{\circ} \mathrm{E}$.

In HadGEM, the along-flow stratification change is large at $65^{\circ}, 75^{\circ}$, and $100^{\circ}-110^{\circ} \mathrm{E}$. At these places, although the stratification becomes weaker, it is still considerably stronger than HiGEM is at the same region. The most striking contrast between the two models is that over $60^{\circ}-100^{\circ} \mathrm{E}$ the surface forcing (dashed lines) acts to destratify the water columns in HiGEM but acts to stratify the water columns in HadGEM. Separating the surface buoyancy loss into its thermal and haline components (not shown), we found that the main contributor is the surface heat fluxes. As discussed earlier, the different surface heat fluxes in the two models for this region are caused by the different SSTs. Now, we see that the difference in SST has a great impact on the upperocean stratification. In HiGEM, the surface buoyancy loss plays a dominant role in destratifying the water columns. This is in contrast to HadGEM, where the advective term (dotted line) is the largest contributor to the destratification.

We now examine the advective term more carefully by separating it into its individual components as expressed in Eq. (6) (Fig. 9, bottom). The mean vertical shear flow [the first term on the r.h.s. of Eq. (6)] in both models acts to weaken the stratification (thick solid lines). This term is dominated by the Ekman flow $\left(\int_{-H}^{0} \overline{\mathbf{u}_{\mathrm{ek}} \cdot \nabla \rho} d z\right)$ (dotted lines). The geostrophic shear flows also stratify the water columns, counterbalancing the northward Ekman transport of dense surface waters in places such as at $72^{\circ} \mathrm{E}$. The Ekman term is similar in both models except at $50^{\circ}-70^{\circ} \mathrm{E}$, where HadGEM is larger. This is explained as follows. The wind stresses in both models are similar (Fig. 3 shows the wind stress vectors and Fig. 6 shows the RMS of the wind stress). However, at $50^{\circ}-70^{\circ} \mathrm{E}$, between the STF and SAF, the meridional gradient of the surface density is stronger in HadGEM than in HiGEM (Fig. 6), leading to a larger $\overline{\mathbf{u}_{\mathrm{ek}} \cdot \nabla \rho}$ there in HadGEM. The reason for these sharper density gradients in HadGEM over this region is not clear.

Another interesting result is in the different eddy contributions in the two models. The eddy contribution comes in two parts: the part due to the vertical shear of the eddies and the part due to the eddy velocity at $400 \mathrm{~m}$ - the second and the third term in Eq. (6), respectively. In HiGEM, the vertical shear part acts to increase the stratification, consistent with the expectation of baroclinic eddies restratifying water columns (dashed line) (Nurser and Zhang 2000). The other part of the eddy contribution also increases the stratification (dashed-dotted line), but its physical meaning is not clear. The sum of the two eddy terms is large compared to the mean vertical shear term (thin solid line) and so the total contribution to the r.h.s. of Eq. (6) from advection is smaller than it otherwise would be without eddies. This is especially clear around $65^{\circ}$ and $75^{\circ} \mathrm{E}$ where the eddy contribution almost completely cancels the Ekman contribution.

The eddy parts in HadGEM are calculated using the parameterized eddy velocity from GM. At $60^{\circ} \mathrm{E}$, the parameterization does produce a small eddy restratification. It seems small since the eddy diffusivity for this region is about 1000-2000 $\mathrm{m}^{2} \mathrm{~s}^{-1}$ (Fig. 11) and the WML depth in HadGEM is much shallower than $400 \mathrm{~m}$ and so should not be affected significantly by the tapering in the GM parameterization. There might be several reasons for this. One is that the density slopes in HadGEM are not steep enough in this region where STF and SAF converge, as seen in Fig. 2. What we suggest here is that there might be an indirect effect of coarse resolution in the sense that without resolving fronts adequately the parameterization in the coarse-resolution model will not be able to reproduce the expected eddy velocity. Another reason for smaller eddy restratification in HadGEM may be that the eddy thickness diffusivity is too small. Observational studies have suggested the 

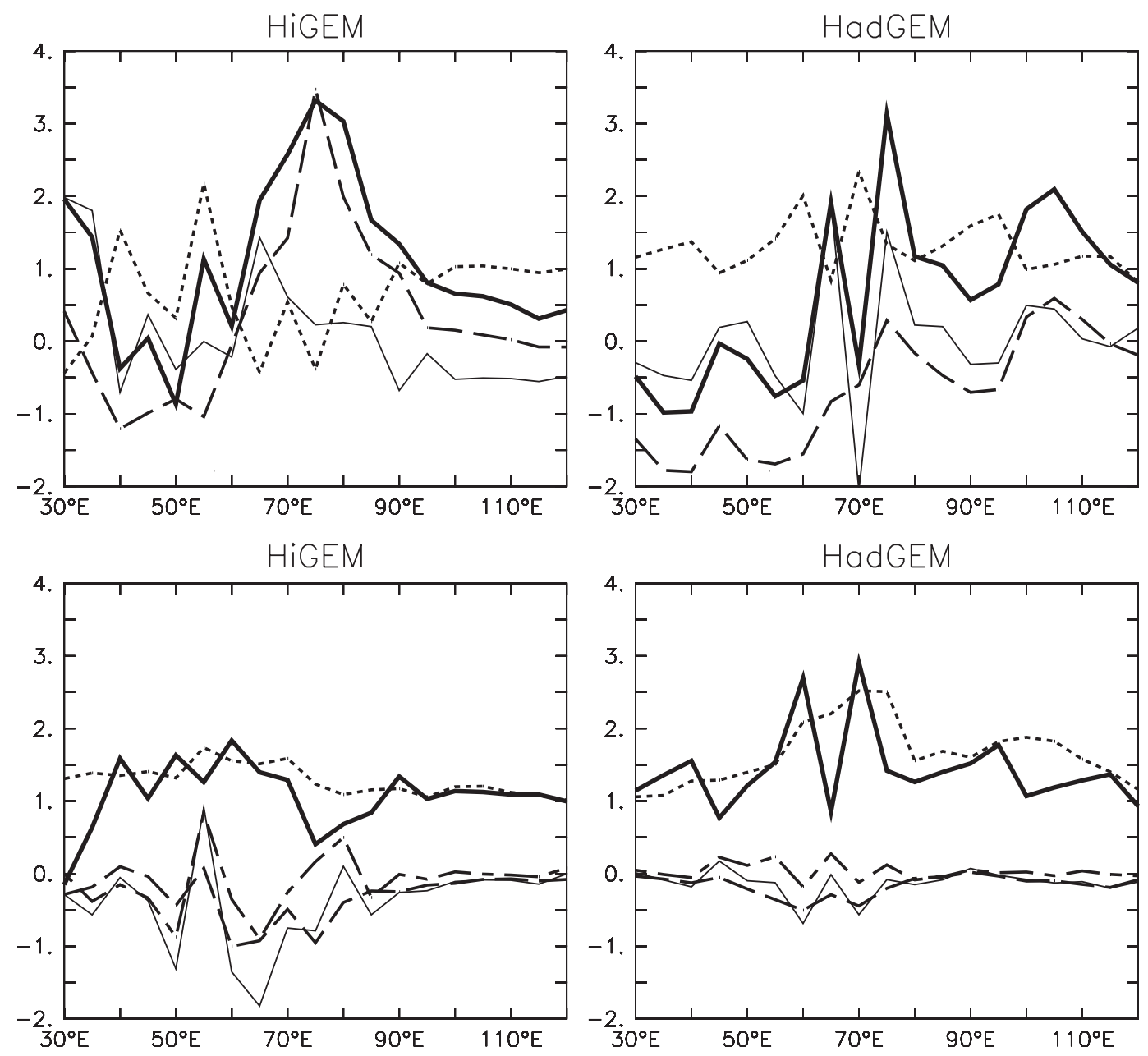

FIG. 9. The 400-m depth-averaged components of Eq. (6) from (left) HiGEM and (right) HadGEM. (top) The thick solid lines are the advective term $\overline{\mathbf{u}}_{0} \cdot \nabla\left(\bar{\rho}-\bar{\rho}_{0}\right)$, the dashed lines are the forcing $\mathcal{F}$, the dotted lines are the sum of the first three terms on the r.h.s. of Eq. (6), and the thin solid lines (calculated as residual) are $\mathcal{W}+\mathcal{D}$. (bottom) The components for the r.h.s of Eq. (6): the thick solid lines are the mean vertical shear term $-\left(\overline{\mathbf{u}}-\overline{\mathbf{u}}_{0}\right) \cdot \nabla \bar{\rho}$, the dotted lines are the Ekman term $-\overline{\mathbf{u}_{\mathrm{ek}} \cdot \nabla \rho}$, the dashed lines are the eddy vertical shear $-\overline{\left(\mathbf{u}^{\prime}-\mathbf{u}_{0}^{\prime}\right) \cdot \nabla \rho^{\prime}}$, the dotted-dashed lines are $-\overline{\mathbf{u}_{0}^{\prime} \cdot \nabla\left(\rho^{\prime}-\rho_{0}^{\prime}\right)}$, and the thin solid lines are the sum of the two eddy terms.

eddy diffusivity to be up to $4000 \mathrm{~m}^{2} \mathrm{~s}^{-1}$ at the surface (Ferreira et al. 2005) and $20000 \mathrm{~m}^{2} \mathrm{~s}^{-1}$ at $60^{\circ} \mathrm{E}$ (Sallée et al. 2008) and models with enhanced surface eddy diffusivity do seem to improve the interior circulations as well as the surface tracer fields (Danabasoglu and Marshall 2007; Vivier et al. 2010). Alternatively, it could be that although HadGEM uses the scheme from Visbeck et al. (1997) to parameterize eddies, it may not work well near topography, as suggested by Hallberg and Gnanadeskan (2001).

In summary, from the comparison of what changes the along-flow stratification in the two models, we found that the surface heat flux has the opposite role in the two models: destratification in HiGEM and stratification in HadGEM. Since the depth of the WML is determined not only by the direct heat loss over the region where the ML is the deepest but also by the accumulative surface fluxes along the flow, the difference in the upstream heat flux is the main reason for the differing WML depths in the two models. We have already discussed in the previous section that the different heat fluxes in the two models are caused by the differing SSTs resulting from the different paths of the Agulhas Return Current.

Eddies also play a role in increasing the along-flow stratification. In some places (e.g., $\left.65^{\circ} \mathrm{E}\right)$, the effects of eddy restratification are large enough to cancel the Ekman density increase. The presence of eddies thus affects the contribution from the vertical shear flow. In HadGEM, Ekman cooling is slightly stronger but eddies are much weaker and so the mean vertical shear 
contribution is large. The along-flow stratification change in HadGEM is mainly due to this Ekman cooling. In contrast, in HiGEM the Ekman cooling is slightly weaker but eddies are stronger and so the mean vertical shear term plays a lesser role in changing the stratification in HiGEM.

Our finding is different from that of Sallée et al. (2006) who, in a heat budget calculation, found a significant role for eddy heat diffusion in surface cooling upstream of the deep WML and that, in comparison, the upstream surface heat loss was less important. However, the resolution in the SST used for climatological surface fluxes is often coarse (in their case $2^{\circ}$ ) and this might affect the heat budget since too large a scale of SST can underestimate the heat loss over eddies and fronts (Rouault et al. 2003). Another difference between our results and theirs is that we found that eddies oppose the Ekman processes for most of the area between $40^{\circ}$ and $80^{\circ} \mathrm{E}$ (except at $55^{\circ} \mathrm{E}$ ) whereas in their case eddies work in the same way as the Ekman processes at $60^{\circ}-80^{\circ} \mathrm{E}$ over the Kerguelen Plateau.

\section{The net subduction south of $30^{\circ} \mathrm{S}$}

Subduction is a process by which water is transferred from the surface mixed layer to the ocean interior. Because the winter mixed layer depths in the two models are very different, we expect the subduction rates will also be different. In particular, we are interested in "permanent subduction," that is, the rate at which water crosses the base of the winter mixed layer and enters into the permanent thermocline. At a given time, the permanent subduction, $s(x, y, t)$, can be calculated from

$$
s(x, y, t)=-\frac{\partial H_{m}}{\partial t}-\nabla \cdot\left(\int_{-H_{m}}^{0} \mathbf{u} d z\right),
$$

where $H_{m}$ is the depth of WML.

First, we compare the models' permanent subduction integrated everywhere south of $30^{\circ} \mathrm{S}$. To do this, $s(x, y, t)$ is calculated using 5-day mean velocity for $\mathbf{u}$ and timemean WML for $H_{m}$ [and so the time tendency term in Eq. (7) vanishes]. This is then binned into 80 predetermined density classes and then averaged over the 10 -yr period to obtain the net subduction:

$$
\operatorname{Sub}_{\mathrm{net}}(\rho)=\frac{1}{T_{10 \mathrm{yr}}} \iint_{\rho \leq \rho^{\prime} \leq \rho+\Delta \rho} s(x, y, t) d A d t,
$$

where $T_{10 \mathrm{yr}}$ is the 10 -yr time period and $d A=d x d y$ is the area per grid cell. Note that the time averaging is taken in density space and not in $(x, y)$ space because density varies with time although $H_{m}$ does not.
Figure 10 (top right) shows the accumulative net subduction, which is the sum of the net subduction for all density classes denser than a given density. In HiGEM, there is an overturning circulation with about $31 \mathrm{~Sv}$ of entrainment of water at density 26.9-27.8 and about $31 \mathrm{~Sv}$ of subduction of water at density $25.7-26.9 \mathrm{~kg} \mathrm{~m}^{-3}$. The density range for the subduction is similar to that in Sallée et al. (2010) (superimposed in Fig. 10). In HadGEM, the net subduction rate is similar to that in HiGEM but occurs at lighter densities $\left(25.3-26.6 \mathrm{~kg} \mathrm{~m}^{-3}\right)$. The different density ranges in the two models for the subduction are due to the different surface density fields, as seen in Fig. 6.

From the kinematic perspective [as defined in Eq. (7)], subduction results from the divergence of the lateral volume transport in the mixed layer. The lateral volume transport can be separated into time-mean and eddy parts. To estimate the subduction due to eddies, we need to exclude the seasonal variability from the time variability as much as possible. This is not trivial because of their similar time scales. As a simple approach, we construct a 1-yr climatology using the 5-day-mean data for the time-mean quantities. The resulting 1-yr climatology removes the interannual variability (which is small) and much eddy variability but retains the seasonal cycle. The subduction calculated from the 1-yr climatology is defined as the mean subduction:

$$
\operatorname{Sub}_{\text {mean }}(\rho)=\frac{1}{T_{1 \mathrm{yr}}} \iint_{\rho \leq \rho^{\prime} \leq \rho+\Delta \rho} s_{\operatorname{clim}}(x, y, t) d A d t,
$$

where $s_{\text {clim }}(x, y, t)=-\nabla \cdot\left(\int_{-H_{m}}^{0} \mathbf{u}_{\text {clim }} d z\right), \mathbf{u}_{\text {clim }}$ is the velocity from the reconstructed climatology, and $T_{1 \mathrm{yr}}$ is the 1-yr time period. The eddy subduction is

$$
\operatorname{Sub}_{\text {eddy }}(\rho)=\operatorname{Sub}_{\text {net }}(\rho)-\operatorname{Sub}_{\text {mean }}(\rho) .
$$

Thus, eddy subduction arises from the correlation between the eddy subduction velocity, $s-s_{\text {clim }}$, and the surface eddy density. Since we use the time-mean winter mixed layer, our definition of eddy subduction does not include the correlation between the eddy subduction velocity and the time-varying mixed layer depth.

In HiGEM, eddy subduction is calculated as described above, and in HadGEM, eddy subduction can be directly calculated from the GM velocity. Both models give a similar eddy-induced net subduction of about $6 \mathrm{~Sv}$ (Fig. 10, bottom right and the insert figure). The eddy subduction value is also similar to that in a model study by Iudicone et al. (2008a). It seems that the eddy subduction from models is small compared to the $28-\mathrm{Sv}$ estimate of Sallée et al. (2010) (superimposed in Fig. 10, bottom right). However, estimating eddy subduction from parameterization is sensitive to the value of the 

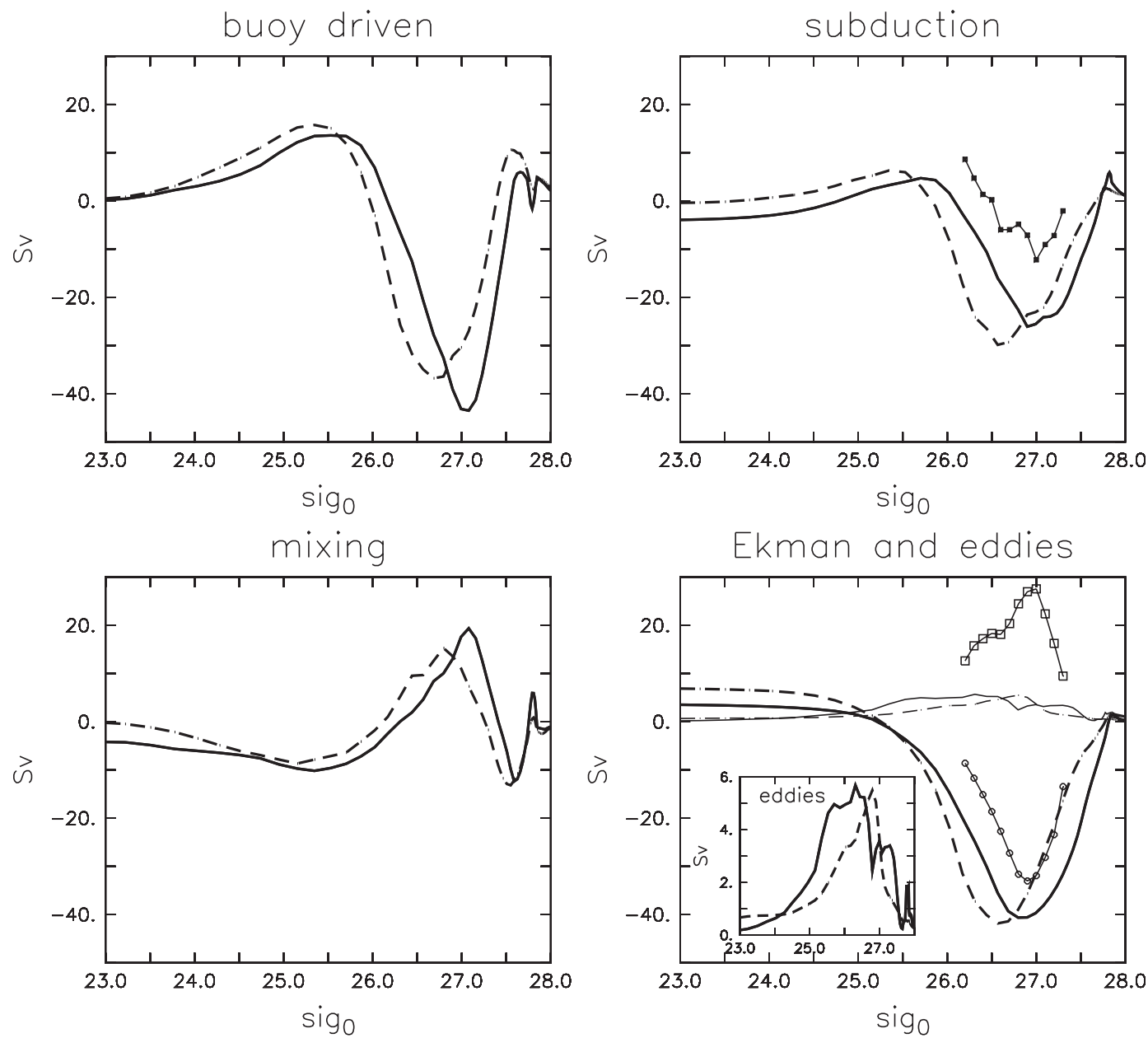

FIG. 10. Quantities integrated as a function of density south of $30^{\circ} \mathrm{S}$. (top left) The buoyancy-flux-driven transformation, (top right) the total subduction (through the base of the WML) of water denser than a given density, and (bottom left) the residual of the total subduction and the buoyancy-flux-driven transformation. (bottom right) Shown are the Ekman pumping (thick lines) and eddy subduction (thin lines). The eddy subduction is also plotted in the insert figure with an expanded $y$ axis for clarity. The solid lines are from HiGEM and the dashed line are from HadGEM. For comparison, the calculations from Sallée et al. (2010) are superimposed for the subduction (top right, filled squares), eddy (bottom right, open squares), and Ekman (bottom right, filled circles).

eddy diffusivity, as illustrated in Sallée et al. (2010, their Fig. 5a). Their estimate of $28 \mathrm{~Sv}$ of eddy subduction is based on an eddy diffusivity of about $4000 \mathrm{~m}^{2} \mathrm{~s}^{-1}$ averaged along the SAF (Sallée et al. 2008). In HadGEM, eddy diffusivity is below $500 \mathrm{~m}^{2} \mathrm{~s}^{-1}$ for most of the Indian Ocean and about $2000 \mathrm{~m}^{2} \mathrm{~s}^{-1}$ between the STF and $\mathrm{SAF}$ at $42^{\circ} \mathrm{S}, 50^{\circ}-70^{\circ} \mathrm{E}$ (Fig. 11 , bottom right). In comparison, the eddy diffusivity in Sallee et al. (2008) at the same location reaches $20000 \mathrm{~m}^{2} \mathrm{~s}^{-1}$, nearly 10 times the value in HadGEM. If instead the eddy diffusivity from Marshall et al. (2006) $\left(\sim 1000-2000 \mathrm{~m}^{2} \mathrm{~s}^{-1}\right)$ is used, the resulting eddy subduction is about $10 \mathrm{~Sv}$, which is close to our calculations.

From a dynamic perspective, it is useful to separate the mean subduction into the part driven by the winds and the remaining part, which is mostly due to geostrophic flows:

$$
\operatorname{Sub}_{\text {mean }}(\rho)=\operatorname{Sub}_{\text {ek }}(\rho)+\operatorname{Sub}_{\text {geo }}(\rho),
$$

where $\operatorname{Sub}_{\mathrm{ek}}=\left(1 / T_{10 \mathrm{yr}}\right) \iint_{\rho \leq \rho^{\prime} \leq \rho+\Delta \rho}-W_{\mathrm{ek}} d A d t, W_{\mathrm{ek}}$ is the Ekman pumping, and Sub geo $_{\text {is }}$ ise residual. There is no substantial difference in the Ekman terms between HiGEM and HadGEM; both give about $41 \mathrm{~Sv}$ of subduction (Fig. 10).

Combining (10) and (11), the subduction is separated into three terms: $\operatorname{Sub}_{\text {net }}=\mathrm{Sub}_{\text {eddy }}+\mathrm{Sub}_{\mathrm{ek}}+\mathrm{Sub}_{\mathrm{geo}}$. In HiGEM, this gives $32_{\text {net }} \sim-6_{\text {eddy }}+41_{\text {ekm }}-3_{\text {geo. }}$. A similar breakdown by Sallée et al. (2010) yields $12_{\text {net }} \sim$ $-28_{\text {eddy }}+33_{\text {ekm }}+7_{\text {geo }}$. Thus, the difference in the net 

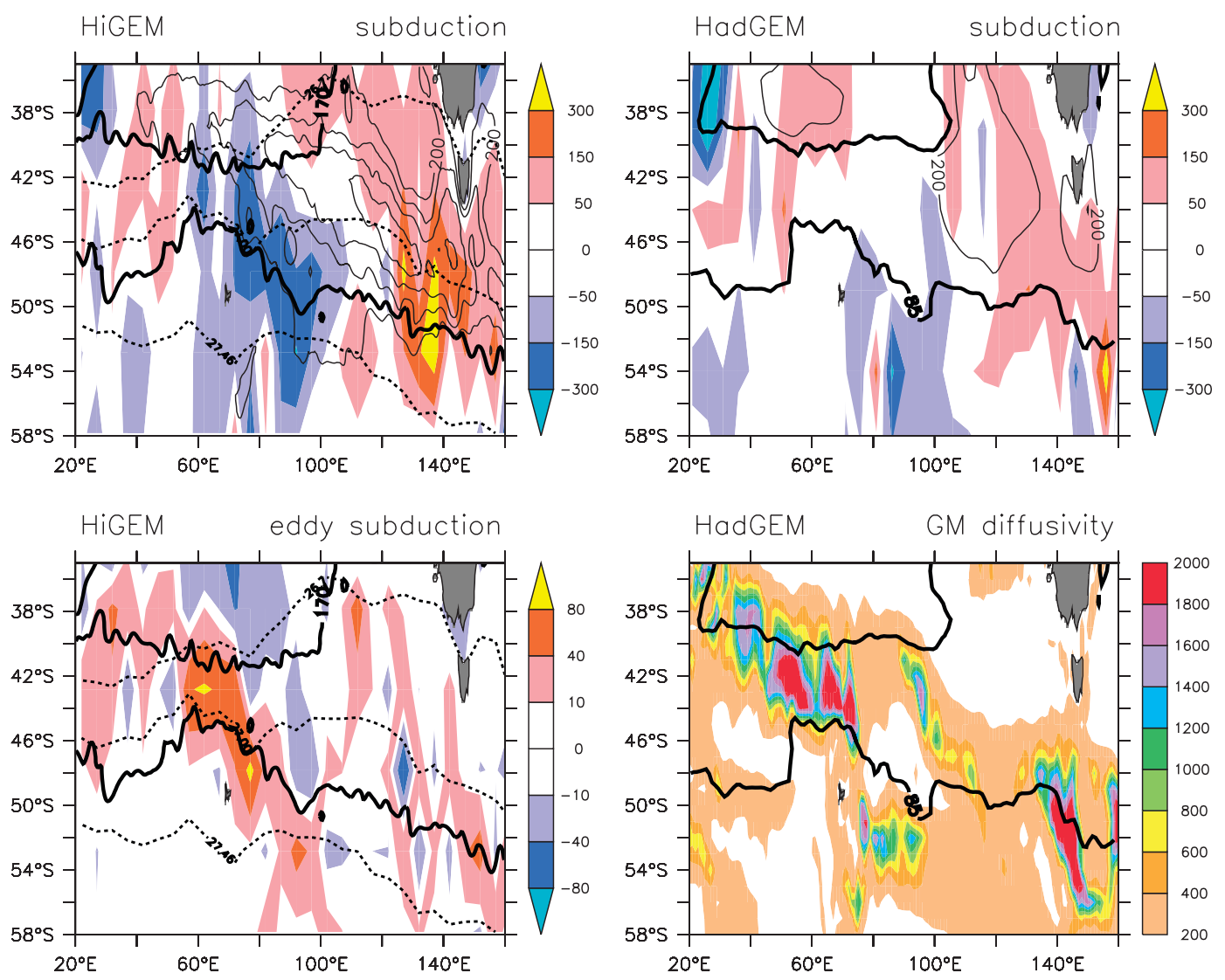

FIG. 11. The top two panels show the remapped total subduction rate ( $\mathrm{m} \mathrm{yr}^{-1}$, colors) from (top left) HiGEM and (top right) HadGEM. The thin black contours are the WML depth, with a 200-m contour interval. (bottom left) The eddy subduction rate $\left(\mathrm{m} \mathrm{yr}^{-1}\right)$ from HiGEM (note that the color scale is different from that in the top two panels). The dotted contours in the left panels mark the time-mean position of $26.7,27.0$, and $27.46 \mathrm{~kg} \mathrm{~m}^{-3}$ densities. (bottom right) The eddy thickness diffusivity $\left(\mathrm{m}^{2} \mathrm{~s}^{-1}\right)$ from HadGEM. The STF and SAF are superimposed (dark contours) in all panels.

subduction between HiGEM and Sallée et al.'s (2010) estimate is mostly due to the difference in the eddy subduction.

From a thermodynamic perspective, Marshall's (1997) formulation says that the subduction is balanced by the surface forcing and eddy mixing. We calculate the surface flux-driven transformation by taking into account the light penetration below the surface, as in Iudicone et al. (2008b). However, this gives only a 4-Sv difference from the calculation using the total shortwave absorption at the surface. This is because the mixed layer depth is on average deeper than the light attenuation depth of $17 \mathrm{~m}$. In HiGEM, the surface buoyancy flux-driven transformation gives $57 \mathrm{~Sv}$ for $25.5 \leq \rho \leq 27 \mathrm{~kg} \mathrm{~m}^{-3}$ with the peak value of $-42 \mathrm{~Sv}$ at $\rho=27.0 \mathrm{~kg} \mathrm{~m}^{-3}$ (Fig. 10, top left). Because of the poorly known surface fluxes in the Southern Ocean, the climatology-based estimates of the surface flux transformation rate at $\rho=$ $27.0 \mathrm{~kg} \mathrm{~m}^{-3}$ vary from $-55 \mathrm{~Sv}$ (Large and Nurser 2001) to $-12 \mathrm{~Sv}$ (Howe and Czaja 2009). In HiGEM, the formation of SAMW $\left(26.5 \leq \rho \leq 27 \mathrm{~kg} \mathrm{~m}^{-3}\right)$ due to the surface flux is $22 \mathrm{~Sv}$, close to the $29 \mathrm{~Sv}$ found by Howe and Czaja (2009). The mixing in the watermass transformation is diagnosed as the residual of the surface flux transformation from the subduction (Fig. 10, bottom left). In this way, the mixing includes the eddy diffusive buoyancy flux, the horizontal and vertical diffusion within the mixed layer and the seasonal thermocline, and the vertical mixing across the base of the winter mixed layer. The mixing in HiGEM is about $20 \mathrm{~Sv}$ at $\rho=$ $27.0 \mathrm{~kg} \mathrm{~m}^{-3}$, close to the values from other models, such as in Iudicone et al. (2008b). In HadGEM both the surface forcing and mixing are noticeably smaller than those in HiGEM.

So far, the comparison shows that for basinwide integrals there are no significant differences between the two models in term of the net subduction and eddy subduction. This is perhaps puzzling since the differences 

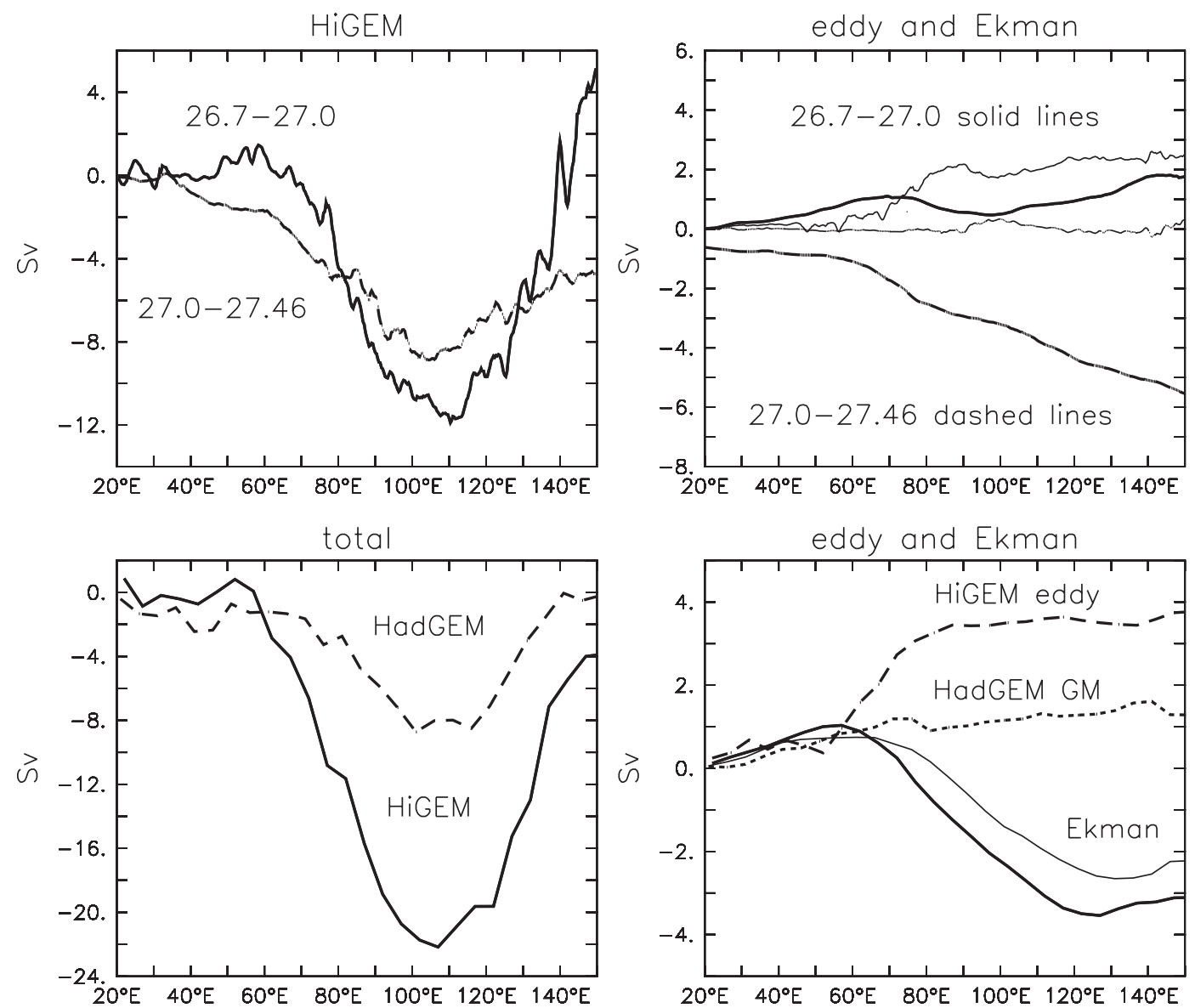

FIG. 12. (top) The accumulative subduction in HiGEM for 26.7-27.0 (solid lines) and 27.0-27.46 $\mathrm{kg} \mathrm{m}^{-3}$ (dashed lines) densities. (left) The total subduction and (right) Ekman pumping (thick lines) and eddy subduction (thin lines). (bottom) The integrated fluxes between $40^{\circ}$ and $58^{\circ} \mathrm{S}$ and accumulated eastward from $20^{\circ} \mathrm{E}$. (left) The total subduction from HiGEM (solid line) and HadGEM (dashed line). (right) The Ekman pumping from HiGEM (thick solid line) and from HadGEM (thin solid line), the eddy subduction from HiGEM (dashed line), and the subduction from the GM parameterization in HadGEM (dotted line).

in the WML depth between the two models are large. The problem is that when integrated over a large region there can be cancellations between subduction and entrainment. We will illustrate next that there are in fact large differences in the local distribution of subduction between the two models.

\section{a. Local distribution}

From the definition of the integrated net subduction Eq. (8), it can be seen that there may be a correlation between the subduction velocity and the surface area bounded by $\rho$ and $\rho+\Delta \rho$, as expressed by $s(x, y, t) d A$. Thus, the total subduction at $(x, y)$ is not just the time mean of $s(x, y)$. To obtain a local distribution of the subduction at a given $x$, we observe that $s(x, y, t) d A=$ $s(x, y, t) d x d y=s(x, y, t)(\partial y / \partial \rho) d \rho d x$. Thus, the local subduction can be defined as a function of $x$ and $\rho$ :

$$
\mathcal{S}(x, \rho, t)=d x \int_{\rho \leq \rho^{\prime} \leq \rho+\Delta \rho} s(x, y, t) \frac{\partial y}{\partial \rho^{\prime}} d \rho^{\prime} .
$$

In this way, the local subduction, $\mathcal{S}(x, \rho)$, captures the correlation between the subduction velocity and the area bounded between isopycnals in the meridional direction and between $x$ and $x+d x$. The time average of $\mathcal{S}(x, \rho, t)$, denoted as $\overline{\mathcal{S}}(x, \rho)$, is the time-mean total subduction. This definition is consistent with Eq. (8) since integrating $\overline{\mathcal{S}}(x, \rho)$ over $x$ gives the net subduction Sub $_{\text {net }}$ in Eq. (8).

The time average $\overline{\mathcal{S}}(x, \rho)$ is a Lagrangian averaging since it follows the density as the density evolves with time and space. As a result, the $y$ position of the subduction is lost. To recover the approximate $y$ position, we use the equivalent latitude, $\tilde{y}(x, \rho)$, defined as the time mean of the inverse function of $\rho(x, y)$. [Note that 
$\tilde{y}(x, \rho)$, is not the inverse function of the time mean of $\rho(x, y)$.] This is possible because over the region between $30^{\circ}$ and $60^{\circ} \mathrm{S}$ the contours of a constant sea surface density lie roughly in the zonal direction and vary monotonically in the meridional direction. The local subduction $\overline{\mathcal{S}}(x, \rho)$ can then be mapped back to $(x, y)$ using the equivalent latitude $\tilde{y}(x, \rho)$, by defining $\tilde{\mathcal{S}}[x, \tilde{y}(x, \rho)] \equiv \overline{\mathcal{S}}(x, \rho)$. To avoid cumbersome notation, we simply use $\tilde{\mathcal{S}}(x, y)$ with the understanding that it is a remapped time-mean total subduction.

We calculate $\mathcal{S}(x, \rho)$ using the 5-day mean data and average over the 10 -yr period to obtain $\overline{\mathcal{S}}(x, \rho)$ To avoid a noisy field, we then calculate the subduction rate on a $5^{\circ}$ grid as follows. The total subduction $\overline{\mathcal{S}}(x, \rho)$ is summed up over $5^{\circ}$ longitude and then divided by the area ( $5^{\circ}$ in longitude and $[\tilde{y}(x, \rho)-\tilde{y}(x, \rho+\Delta \rho)]$ in latitude). Figure 11 (top) shows the subduction rate (positive is subduction and negative is entrainment) after mapping back to a $5^{\circ}$-latitude grid using $\tilde{y}(x, \rho)$. The larger values are found mainly around the deep WML region (superimposed in Fig. 11) with entrainment on the upstream side of the deep WML and subduction on the downstream side. This is because, following the flow, the deepening of WML requires entrainment and the shallowing of WML results in subduction. Both models have similar patterns of entrainment and subduction, although the rate is much higher in HiGEM as a consequence of the deeper WML. The distribution of the local subduction in HiGEM is similar that found by Sallee et al. (2010). At $70^{\circ}-80^{\circ} \mathrm{E}$, both HiGEM and Sallée et al. (2010) have large entrainment of more than $200 \mathrm{~m} \mathrm{yr}^{-1}$ whereas in HadGEM the entrainment is no more than $150 \mathrm{~m} \mathrm{yr}^{-1}$.

To relate the local distribution of the subduction to the densities of the subducted waters, we first plot the remapped mean density using the time-mean position of density $\tilde{y}$ as explained earlier. For HiGEM, the densities $\rho=26.7,27.0$, and $27.46 \mathrm{~kg} \mathrm{~m}^{-3}$ are superimposed in Fig. 11 (top left). Consider the accumulative subduction in two density classes with the density ranges 26.7$27.0 \mathrm{~kg} \mathrm{~m}^{-3}$ and $27.0-27.46 \mathrm{~kg} \mathrm{~m}^{-3}$. In each density class, there is a cancellation between the entrainment and subduction and so the integrated subduction is much smaller than the local entrainment-subduction (Fig. 12, top left). Similar cancellation also occurs in HadGEM although at different density classes (not shown). This explains why the net subduction (Fig. 10) obtained from integrating over the entire region does not show large differences between HiGEM and HadGEM.

To quantify the difference between HiGEM and HadGEM, we choose to integrate the remapped total subduction over fixed geographical locations rather over fixed density classes. This is because the two models do not subduct water of the same density. In addition, both Figs. 11 and 12 (top left) show that the cancellation between the entrainment and subduction occurs mainly at the same density rather than between different density values and so the meridional integrated subduction should have little cancellation. We integrate subduction over the region $40^{\circ}-58^{\circ} \mathrm{S}$ and plot the accumulative subduction (Fig. 12 , bottom left). Over $110^{\circ}-150^{\circ} \mathrm{E}$, the difference between the two models is as large as $10 \mathrm{~Sv}$. This large difference is not seen from the integrated net subduction. In the next section, we will show that the difference is mainly due to geostrophic flows in the WML.

\section{b. Eddy subduction}

To calculate the local distribution of eddy subduction, we first calculate the local distribution of the mean subduction. Because of the seasonal cycle in the models, we use the reconstructed 1-yr climatology to calculate the mean subduction following the same time-averaging and remapping exercise as in section 4a. In other words, the mean subduction $\tilde{\mathcal{S}}_{\text {clim }}(x, y)$ is the remapped $\overline{\mathcal{S}}_{\text {clim }}(x, \rho)$, where $\mathcal{S}_{\text {clim }}(x, \rho)$ is as in Eq. (12) but now replacing $s(x, y, t)$ with $s_{\text {clim }}(x, y, t)$, and overbar is the 1-yr average. Note that the mean subduction $\tilde{\mathcal{S}}_{\text {clim }}(x, y)$ is not the simple Eulerian averaging at $(x, y)$. This is because surface density varies with season and is not exactly monotonic meridionally. Once the mean subduction is defined, the local eddy subduction is $\overline{\mathcal{S}}_{\text {eddy }}(x, \rho)=\overline{\mathcal{S}}(x, \rho)-\overline{\mathcal{S}}_{\text {clim }}(x, \rho)$, which can be then remapped to obtain $\tilde{\mathcal{S}}_{\text {eddy }}(x, y)=\tilde{\mathcal{S}}(x, y)-\tilde{\mathcal{S}}_{\text {clim }}(x, y)$. If $\overline{\mathcal{S}}_{\text {eddy }}(x, \rho)$ is integrated over $x$, then we recover the $\operatorname{Sub}_{\text {eddy }}(\rho)$ in Eq. (10).

The eddy subduction in HiGEM is small except over the convergence zone between the STF and SAF (Fig. 11 , bottom left). The eddy subduction rate at $48^{\circ} \mathrm{S}, 77^{\circ} \mathrm{E}$ reaches $94 \mathrm{~m} \mathrm{yr}^{-1}$, which is about half of the total subduction rate of $-170 \mathrm{~m} \mathrm{yr}^{-1}$ at the same location. The eddy subduction rate at $42^{\circ} \mathrm{S}, 62^{\circ} \mathrm{E}$, is $85 \mathrm{~m} \mathrm{yr}^{-1}$, which is about $40 \%$ of the total subduction rate of $-215 \mathrm{~m} \mathrm{yr}^{-1}$. Our results differ from those of Sallée et al. (2010). Their estimates show a consistent picture of eddy entrainment on the north side of the SAF and subduction on the south side of the Polar Front. This is, by construction, the combination of eddy parameterization and a steeper density gradient across the fronts. In our case, the spatial distribution of the eddy subduction is sparse and the large eddy subduction is only found at the convergence zone of the STF and SAF.

How does eddy subduction compare to Ekman transport? To compare like with like, the Ekman pumping is binned in density space using the same procedure as for binning the subduction (Fig. 12, top right). For the lighter density class $\left(26.7-27.0 \mathrm{~kg} \mathrm{~m}^{-3}\right)$, both eddies and Ekman pumping indicate a 2-Sv 
subduction over $0^{\circ}-150^{\circ} \mathrm{E}$. For the heavier density class (27.0-27.46 $\left.\mathrm{kg} \mathrm{m}^{-3}\right)$, there is almost no eddy contribution while Ekman gives an net entrainment of $5 \mathrm{~Sv}$. Unlike the total subduction seen earlier in Fig. 12 (top left), there is little local cancellation between the entrainment and subduction within the same density class for the Ekman pumping. It can also be seen that, for the local distribution of subduction, both eddy subduction and Ekman pumping are small compared to the total subduction, which suggests that the geostrophic flow plays a significant role.

Figure 12 (bottom right) shows the accumulative eddy subduction and Ekman pumping integrated between $42^{\circ}$ and $58^{\circ} \mathrm{S}$. In HiGEM, between $60^{\circ}$ and $90^{\circ} \mathrm{E}$, the eddy subduction is $2.4 \mathrm{~Sv}$, as opposed to the Ekman pumping of $-2.3 \mathrm{~Sv}$. In HadGEM, the subduction due to the GM parameterization is much smaller $(\sim 1 \mathrm{~Sv})$ and so there is little cancellation between the Ekman pumping and eddy subduction. The geostrophic flow contribution (Fig. 12, the difference between the bottom-left and bottom-right panels) is much larger in HiGEM than in HadGEM, which is likely due to the much deeper mixed layer and stronger flow in HiGEM.

As before, the role of the eddies is not represented very well locally by the GM parameterization, although when integrating over the large area one seems to get the impression of fairly good eddy subduction from the parameterization. The shortcoming of the weakly parameterized local eddy subduction in HadGEM could be due to either the WML not being well represented (e.g., incorrect distribution and incorrect depth) and/or that the eddy velocity is too weak. The latter may be improved by, say, increasing the eddy diffusivity and by better parameterization, as discussed in section 3 . The former involves additional factors from the far field, which are not so easily parameterized, such as the sensitivity of surface fluxes to the pathway of the Agulhas Return Current, as discussed in section 2.

\section{Summary}

One of most frequently asked questions in climate modeling is whether it is necessary to resolve mesoscale eddies in the ocean in order to accurately predict future climate. In this paper, we compare the winter mixed layer depth and subduction in the southern Indian Ocean in an ocean-atmosphere coupled model where the horizontal resolutions in the ocean are set to $1^{\circ}$ and $1 / 3^{\circ}$. Although neither resolves the eddies adequately, the differences in the resolved dynamics between them are sufficiently large that understanding the cause of their differences will help to assess the need to resolve eddies in climate models.
In essence, the rate of subduction of water masses is set by the depth of the winter mixed layer. Therefore, the first step is to ensure that the winter mixed layer depth is well represented in the model. We found that the winter mixed layer is better simulated in the southern Indian Ocean in terms of the depth and the spatial distribution in the model with a higher-resolution ocean. The reasons are outlined below.

1) The Agulhas Current continues farther south after leaving the coast. Consequently, the SST south of the STF in the Indian Ocean is higher and so even though the atmosphere is also warmer there is a greater airsea temperature difference and a greater heat loss.

2) The accumulated heat loss between the STF and SAF is crucial for setting the WML depth. With a greater heat loss upstream, stratification between the two fronts is destroyed and so the mixed layer becomes deeper downstream.

The above may be attributed to the indirect effects of higher horizontal resolution in the model. By this we mean that the spatial distribution of the SSTs and surface heat flux is closely tied to the path of the Agulhas Current system, which is sensitive to the resolution of the ocean grid. Although in the coarse-resolution model the southward extension of the Agulhas Current (and thus the surface heat fluxes) may be improved by increasing the eddy diffusivity, this creates a diffusive boundary current, which is not necessarily desirable (Boudra and Chassignet 1988).

There is also evidence of the direct effects of resolving eddies on the WML depth. The vertical shear of the eddy flow near the Kerguelen Plateau provides a restratification, which compensates the densification of the northward Ekman transport. In the coarse-resolution model the eddy restratification is not well reproduced despite the GM parameterization and the horizontal diffusion throughout the top $20 \mathrm{~m}$. The possible remedies are to increase the eddy diffusivity near the surface or to improve the eddy parameterization near the topography.

The effects of eddies on the WML are nonlocal, as they operate over the Kerguelen Plateau, upstream of where the WML is the deepest. This supports the "upstream eddy preconditioning" hypothesis of Sallée et al. (2006) in that they found that eddy diffusive heat flux divergence is strongest over the Kerguelen Plateau. However, we found that upstream surface heat loss (not eddies) is responsible for the deeper WML in HiGEM whereas in their study the upstream surface heat loss plays a lesser role.

The surface heat flux field in HiGEM is very different from that of the NCEP-National Center for Atmospheric Research (NCAR) reanalysis data (used in 
many studies) over this region. It may be that the SST field used for the NCEP-NCAR atmosphere fluxes is too coarse to locate correctly the warm STF. If the SST fields used for reanalysis products were at higher resolutions, then the air-sea temperature difference would be larger. Nonaka et al. (2009) showed that the meridional gradients of the air-sea temperature difference are sharpened at $42^{\circ} \mathrm{S}$ in the Indian Ocean when using a $14^{\circ}$ SST field for reanalysis data. Naturally, one would expect that the magnitude and spatial distribution of the surface flux fields would also be improved with a higherresolution SST field. Another possibility is simply that HiGEM has too much heat loss. To be more certain about the relative roles of the surface forcing and eddies in setting the WML depth, both models and the surface fluxes data need to have sufficient resolution in frontal regions.

The conventional watermass transformation diagnosis is often used to compare between models and between models and observations. Because such diagnoses are based on the integrals over a large area, they miss local variations in watermass formation. For the two models we compared, even though the mixed layer depths differ substantially, the net subductions south of $30^{\circ} \mathrm{S}$ are similar. We have proposed a way to diagnose the local subduction as a function of $(x, \rho)$, which captures the zonal variations of subduction. The total local subduction in HiGEM compares well with the estimate from the observations in terms of locations of entrainment and subduction. The magnitude of the subductionentrainment is smaller than in the observations, but the eddy subduction is uncertain from the observations. With this diagnosis, we can also demonstrate the large local differences in subduction between the two models and the cancellation between the subduction and entrainment at different longitudes within a given density.

Near topographic features, such as the Kerguelen Plateau, the eddy subduction is found to be large compared to the Ekman entrainment. This feature (like the eddy restratification at the Kerguelen Plateau) is not well reproduced in the coarse-resolution model with the GM parameterization. This may simply be the result of incorrect WML depths in the coarse-resolution model and so the problem could be resolved by improving the WML depth in the coarse-resolution model (although how to do this is not clear). Alternatively, it may be that the parameterized eddy velocity needs to be stronger and this might be achieved by enhanced eddy diffusivity at the surface or through a better formulation of the eddy parameterization, especially near topographic features.

In conclusion, the benefit of higher ocean resolution in coupled models is that it resolves smaller-scale SST distributions and thus should give more realistic surface fluxes. This is crucial for setting the WML depth and thus the subduction of water masses. Indeed, the WML in the higher-resolution model is better than that in the lower-resolution model. However, the fact that WML in HiGEM seems too deep suggests that even at eddypermitting resolution, the model still misses some physics. Could this be caused by too strong of a heat loss? It is difficult to tell without high spatial resolution surface flux data. Alternatively, it may be that mesoscale eddies and submesoscale eddies also need to be parameterized in the eddy-permitting climate models, as both processes act to restratify the water column and reduce the mixed layer depth (Nurser and Zhang 2000; Fox-Kemper et al. 2008). For the coarse-resolution models, it is clear that WML depth needs to be improved. In the southern Indian Ocean, it appears that the depth of WML is controlled by the upstream processes. A clear priority is to improve the path of the Agulhas Current system and thus the surface heat fluxes.

Acknowledgments. This work is supported by the U.K. HiGEM project funded through NERC. The authors thank Jeremy Grist and Elizabeth Kent for their advice on the NCEP-NCAR and ERA data. We also thank David Smeed and David Stevens for commenting on the draft and two referees for giving constructive comments on the manuscript.

\section{REFERENCES}

Boudra, D. B., and E. P. Chassignet, 1988: Dynamics of Agulhas retroflection and ring formation in a numerical model. Part I: The vorticity valance. J. Phys. Oceanogr., 18, 280-303.

Boyer, T., S. Levitus, H. Garcia, R. A. Locarnini, C. Stephens, and J. Antonov, 2005: Objective analyses of annual, seasonal, and monthly temperature and salinity for the World Ocean on a $0.25^{\circ}$ grid. Int. J. Climatol., 25, 931-945.

Cerovečki, I., and J. Marshall, 2008: Eddy modulation of air-sea interaction and convection. J. Phys. Oceanogr., 38, 65-83.

Cushman-Roisin, B., 1987: Subduction. Dynamics of the Ocean Surface Mixed Layer, P. Muller and D. Henderson, Eds. Hawaii Institute of Geophysical Special Publications, 181-196.

Danabasoglu, G., and J. Marshall, 2007: Effects of vertical variations of thickness diffusivity in an ocean general circulation model. Ocean Modell., 18, 122-141.

de Boyer Montégut, C., G. Madec, A. S. Fischer, A. Lazar, and D. Iudicone, 2004: Mixed layer depth over the global ocean: An examination of profile data and a profile-based climatology. J. Geophys. Res., 109, C12003, doi:10.1029/2004JC002378.

Dong, S., J. Sprintall, S. T. Gille, and L. Talley, 2008: Southern Ocean mixed-layer depth from Argo float profiles. J. Geophys. Res., 113, C06013, doi:10.1029/2006JC004051.

England, M. H., J. S. Godfrey, A. C. Hirst, and M. Tomczak, 1993: The mechanism for Antarctic Intermediate Water renewal in a World Ocean model. J. Phys. Oceanogr., 23, 1553-1560.

Ferreira, D., J. Marshall, and P. Heimbach, 2005: Estimating eddy stresses by fitting dynamics to observations using 
a residual-mean ocean circulation model and its adjoint. J. Phys. Oceanogr., 35, 1891-1910.

Fox-Kemper, B., and R. Ferrari, 2008: Parameterization of mixed layer eddies. Part II: Prognosis and impact. J. Phys. Oceanogr., 38, 1166-1179.

— — - and R. Hallberg, 2008: Parameterization of mixed layer eddies. Part I: Theory and diagnosis. J. Phys. Oceanogr., 38, $1145-1165$.

Gent, P. R., and J. C. McWilliams, 1980: Isopycnal mixing in ocean circulation models. J. Phys. Oceanogr., 20, 150-155.

Griffies, S. M., A. Gnanadesikan, R. C. Pacanowski, V. D. Larichev, J. K. Dukowicz, and R. D. Smith, 1998: Isoneutral diffusion in a $z$-coordinate ocean model. J. Phys. Oceanogr., 28, $805-830$.

Grist, J. P., and S. A. Josey, 2003: Inverse analysis adjustment of the SOC air-sea flux climatology using ocean heat transport constraints. J. Climate, 16, 3274-3295.

Hallberg, R., and A. Gnanadeskan, 2001: An exploration of the role of transient eddies in determining the transport of a zonally reentrant current. J. Phys. Oceanogr., 31, 33123330 .

Howe, N., and A. Czaja, 2009: A new climatology of air-sea density fluxes and surface water mass transformation rates constrained by WOCE. J. Phys. Oceanogr., 39, 1432-1447.

Iudicone, D., G. Madec, B. Blanke, and S. Speich, 2008a: The role of Southern Ocean surface forcings and mixing in the global conveyor. J. Phys. Oceanogr., 38, 1377-1400.

—, - - and T. J. McDougall, 2008b: Water-mass transformations in a neutral density framework and the key role of light penetration. J. Phys. Oceanogr., 38, 1357-1376.

Karsten, H. K., and J. Marshall, 2002: Constructing the residual circulation of the ACC from observations. J. Phys. Oceanogr., 32, 3315-3327.

Karstensen, J., and D. Quadfasel, 2002: Formation of Southern Hemisphere thermocline waters: Water mass conversion and subduction. J. Phys. Oceanogr., 32, 3020-3038.

Kraus, E. B., and J. S. Turner, 1967: A one-dimensional model of the seasonal thermocline II. The general theory and its consequences. Tellus, 19, 98-106.

Large, W., and A. Nurser, 2001: Ocean surface water mass transformation. Ocean Circulation and Climate: Observing and Modelling the Global Ocean, J. Church and J. Gould, Eds., Academic Press, 317-336.

Marshall, D., 1997: Subduction of water masses in an eddying ocean. J. Mar. Res., 55, 201-222.
Marshall, J., E. Shuckburgh, H. Jones, and C. Hill, 2006: Estimates and implications of surface eddy diffusivity in the Southern Ocean derived from tracer transport. J. Phys. Oceanogr., 36, 1806-1821.

McCartney, M. S., 1982: The subtropical recirculation of mode waters. J. Mar. Res., 40 (Suppl.), 427-464.

Nonaka, M., H. Nakamura, B. Taguchi, N. Komori, A. KuwanoYoshida, and K. Takaya, 2009: Air-sea heat exchanges characteristic of a prominent midlatitude oceanic front in the south Indian Ocean as simulated in a high-resolution coupled GCM. J. Climate, 22, 6515-6535.

Nurser, A. J. G., and J. W. Zhang, 2000: Eddy-induced mixed layer shallowing and mixed layer/thermocline exchange. J. Geophys. Res., 105 (C9), 21 851-21 868.

Oschlies, A., 2002: Improved representation of upper-ocean dynamics and mixed layer depths in a model of the North Atlantic on switching from eddy-permitting to eddy-resolving grid resolution. J. Phys. Oceanogr., 32, 2277-2298.

Rouault, M., C. J. C. Reason, J. R. E. Lutjeharms, and A. C. M. Beljaar, 2003: Underestimation of latent and sensible heat fluxes above the Agulhas Current in NCEP and ECMWF analyses. J. Climate, 16, 776-782.

Sabine, C. L., and Coauthors, 2004: The oceanic sink for anthropogenic $\mathrm{CO}_{2}$. Science, 305, 367-371.

Sallée, J.-B., N. Wienders, K. Speer, and R. Morrow, 2006: Formation of subantarctic mode water in the southeastern Indian Ocean. Ocean Dyn., 56, 525-542.

—, K. Speer, R. Morrow, and R. Lumpkin, 2008: An estimate of Lagrangian eddy statistics and diffusion in the mixed layer of the Southern Ocean. J. Mar. Res., 66, 441-463.

,,-- S. R. Rintoul, and S. Wijffels, 2010: Southern Ocean thermocline ventilation. J. Phys. Oceanogr., 40, 509-529.

Shaffrey, L. C., and Coauthors, 2009: UK-HiGEM: The new U.K. High-Resolution Global Environment Model-Model description and basic evaluation. J. Climate, 22, 1861-1896.

Sloyan, B. M., and I. V. Kamenkovich, 2007: Simulation of Subantarctic Mode and Antarctic Intermediate Waters in climate models. J. Climate, 20, 5061-5080.

Visbeck, M., J. Marshall, T. Haine, and M. Spall, 1997: Specification of eddy transfer coefficients in coarse-resolution ocean circulation models. J. Phys. Oceanogr., 27, 381-402.

Vivier, F., D. Iudicone, F. Busdraghi, and Y.-H. Park, 2010: Dynamics of sea-surface temperature anomalies in the Southern Ocean diagnosed from a 2D mixed-layer model. Climate Dyn., 34, 153-184. 